University of Texas at El Paso

\title{
DigitalCommons@UTEP
}

Open Access Theses \& Dissertations

2012-01-01

\section{Disparities In Park Availability, Features, And Characteristics By Social Determinants Of Health Within A U.s.-Mexico Border Urban Area}

Amir Kamel

University of Texas at El Paso, amir3336@yahoo.com

Follow this and additional works at: https://digitalcommons.utep.edu/open_etd

Part of the Environmental Law Commons, Environmental Policy Commons, Environmental $\underline{\text { Sciences Commons, and the Public Health Education and Promotion Commons }}$

\section{Recommended Citation}

Kamel, Amir, "Disparities In Park Availability, Features, And Characteristics By Social Determinants Of Health Within A U.s.-Mexico Border Urban Area" (2012). Open Access Theses \& Dissertations. 2116.

https://digitalcommons.utep.edu/open_etd/2116 


\title{
DISPARITIES IN PARK AVAILABILITY, FEATURES, AND CHARACTERISTICS BY SOCIAL DETERMINANTS OF HEALTH WITHIN A U.S.-MEXICO BORDER URBAN AREA
}

\author{
AMIR KAMEL \\ Department of Public Health Sciences \\ Master of Public Health Program
}

\begin{abstract}
APPROVED:
\end{abstract}
Oralia Loza, Ph.D., Chair

Gabriel Ibarra-Mejia, M.D., Ph.D.

George King, Ph.D.

Benjamin C. Flores, Ph.D.

Interim Dean of the Graduate School 


\section{Copyright (C)}

by

Amir Kamel

2012 


\section{Dedication}

I would like to dedicate this body of work to my family for all their support during my academic ventures.

Thank you mom and dad, I could not have done it without you. 


\title{
DISPARITIES IN PARK AVAILABILITY, FEATURES, AND \\ CHARACTERISTICS BY SOCIAL DETERMINANTS OF HEALTH WITHIN A \\ U.S.-MEXICO BORDER URBAN AREA \\ by
}

AMIR KAMEL, B.S.

\author{
THESIS \\ Presented to the Faculty of the Graduate School of \\ The University of Texas at El Paso \\ in Partial Fulfillment \\ of the Requirements \\ for the Degree of
}

MASTER OF PUBLIC HEALTH

Department of Public Health Sciences

THE UNIVERSITY OF TEXAS AT EL PASO

May 2012 


\section{Acknowledgements}

First, I would like to give my upmost appreciation to Dr. Paula Ford for providing me with the initiative to focus on the built environment and physical activity; and for encouraging, supporting and guiding me in the right direction. I would also like to express my deepest gratitude to Dr. Oralia Loza and Dr. Andrew Kaczynski for their invested time, expertise, and patience during the course of the study.

Additionally, I would like to recognize Dr. George King and Dr. Gabriel Ibarra-Mejia for sitting on my committee and providing me with feedback, which enhanced my thesis. I would also like to show my appreciation to the faculty and staff of the University of Texas at El Paso.

Finally, I would like to thank my family, my MPH cohort, and everyone else who supported me throughout the course of my academic career. 


\begin{abstract}
Background: Parks have been shown to be a key feature in the built environment that promote physical activity and positively influence health. However, a number of studies have highlighted that park availability, park features (e.g., park facilities, amenities, and aesthetic features), and park characteristics (e.g., quality/safety concerns of the park and surrounding neighborhood) are not equally distributed across neighborhoods in the U.S, specifically areas of low socioeconomic status and diverse racial/ethnic composition. The overall aim of this study was to examine and describe park availability, park features, and park characteristics, and determine their association with two social determinants of health (i.e., median household income and percent foreign-born) in a predominately Hispanic border community.
\end{abstract}

Methods: Park availability (i.e., number of parks) per census tract was obtained from geographical information system (GIS) shape files. Park features and park characteristics were assessed using the Community Park Audit Tool survey instrument. Median household income and percent foreign-born per census tract were extracted from the 2005-2009 American Community Survey for the City of El Paso and used as tertiles labeled as low, medium, and high. Univariate analysis and bivariate associations between park measures and social determinates of health tertiles were conducted using ANOVA for normally distributed variables and Kruskal-Wallis for variables that were not normally distributed using SPSS V19. Multiple pairwise comparisons were conducted for significant bivariate associations.

Results: In the City of El Paso, overall park availability significantly differed by median household income, but only between the medium and high income tertiles. Park facilities and park amenities significantly differed across median household income tertiles; park aesthetic features did not. For park facilities, the medium income tertile was significantly different from both, the low and high income tertiles. The number of park facilities, amenities, and aesthetic features did not differ significantly by percent foreign-born tertiles. Park quality concerns and neighborhood safety concerns significantly differed by median household income and percent foreign-born tertiles. The number of park quality concerns in the high income tertile was significantly different from the low and medium 
income tertiles. The number of neighborhood safety concerns for the low foreign-born tertile significantly differed from the medium and high tertiles.

Conclusions: This study further demonstrates that publically available recreational facilities, and their features and characteristics, are not equally distributed across neighborhoods based on income and foreign-born composition. Future research should consider the quality of park features and better assess their characteristics by neighborhood composition, and identify how access to recreational facilities affects physical activity and other health outcomes. Community members, public health researchers, and policy makers need to work together to facilitate processes to make parks more accessible, usable, and safe for physical activity. 


\section{Table of Contents}

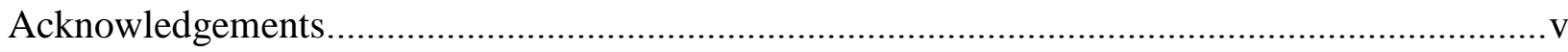

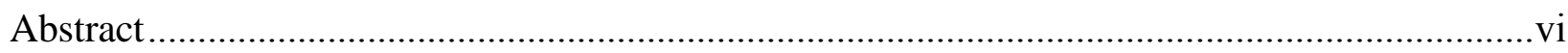

Table of Contents .............................................................................................................. viii

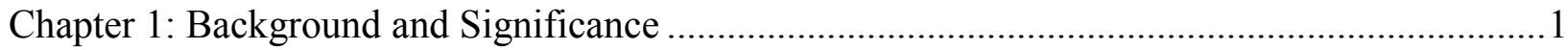

Epidemiology of Obesity and Physical Activity ............................................................ 1

Social Determinants of Health ................................................................................2

The Built Environment and Parks...................................................................................5

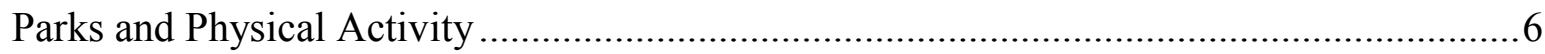

Parks, Social Determinants of Health, and Disparities .................................................. 11

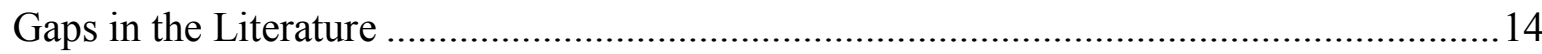

Statement of the Problem............................................................................... 15

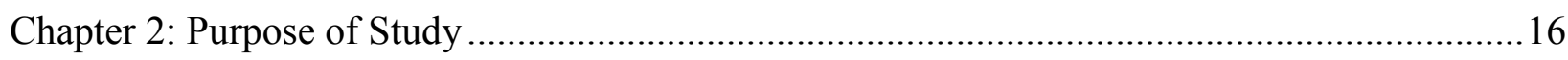

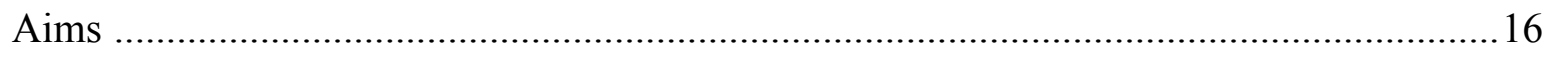

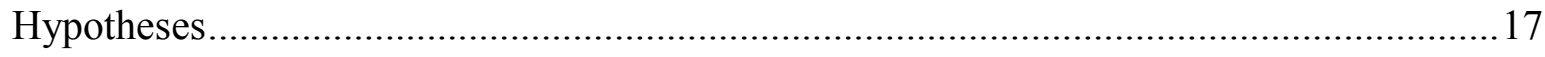

Chapter 3: Methods and Materials ........................................................................................ 18

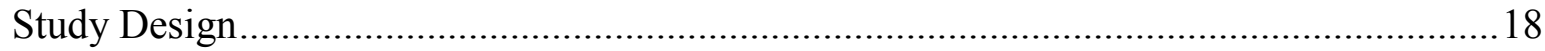

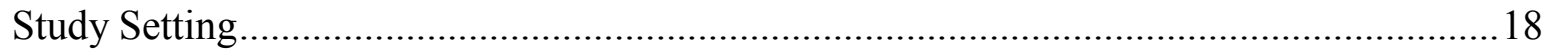

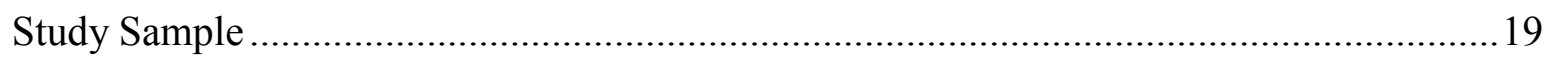

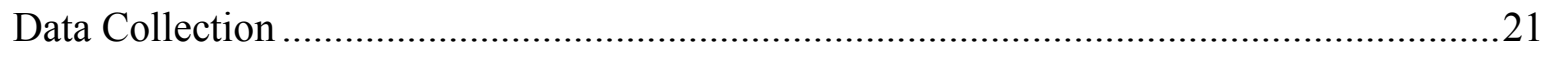

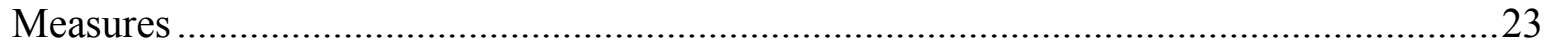

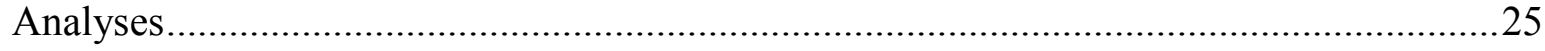

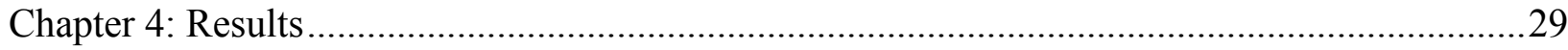

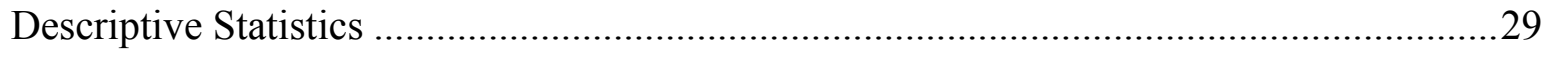

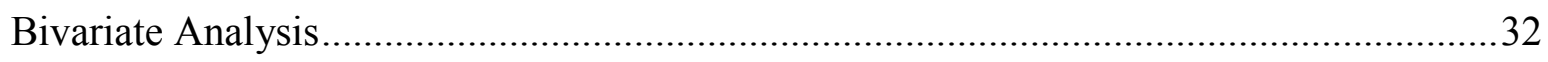

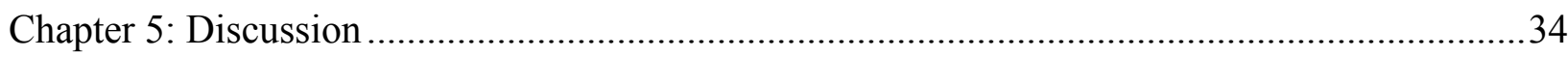

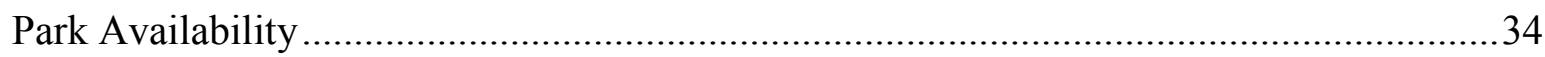

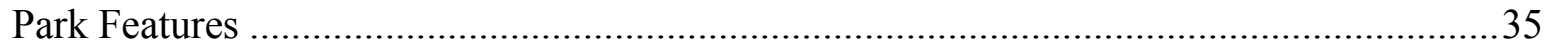

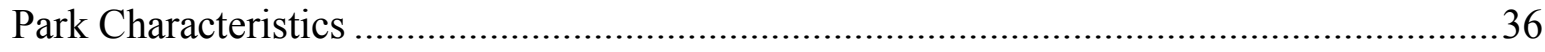

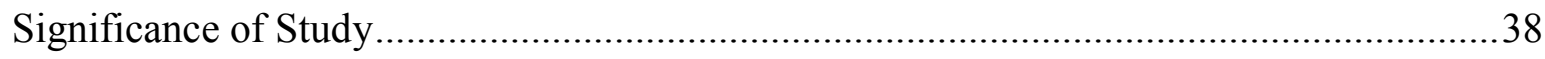




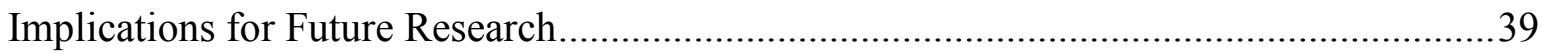

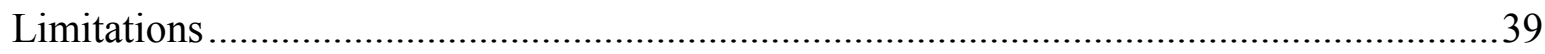

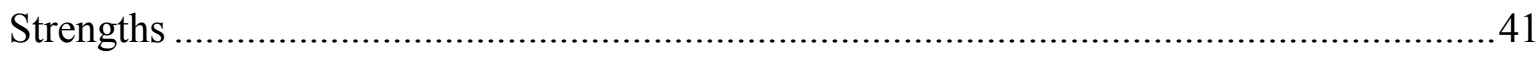

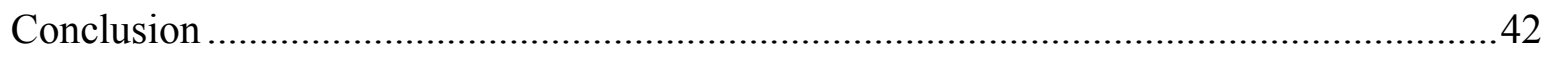

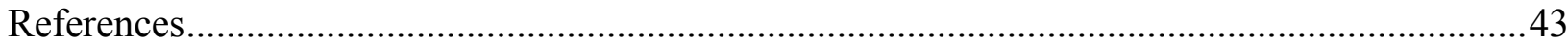

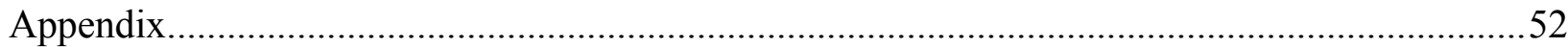

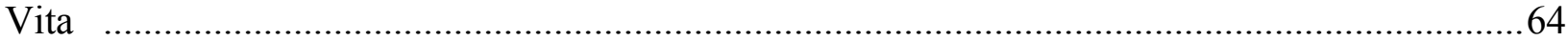




\section{Chapter 1: Background and Significance}

\section{EPIDEMiology of Obesity ANd Physical ACTIVITy}

In the United States, obesity, classified as having a BMI of 30.0 or higher, has reached epidemic proportions, with more than $32 \%$ of adult men and $35.5 \%$ of adult women classified as obese (Flegal, Carroll, Ogden, \& Curtin, 2010). Approximately 17\% of U.S. children and adolescents aged 2-19 years are also classified as obese, or having BMI values at or above the 95th percentile (Ogden, Carroll, Curtin, Lamb, \& Flegal, 2010). Obesity trends vary significantly by age and racial/ethnic group (Center for Disease Control and Prevention [CDC], 2009a; Flegal, Carroll, Ogden, \& Curtin, 2010; Ogden et al., 2010), with Non-Hispanic blacks having the highest rates of obesity (44.1\%), compared with Hispanics (37.9\%) and non-Hispanic Whites (32.6\%) (Flegal et al., 2010). Having excess body weight can lead to an increased risk for certain health concerns, such as high blood pressure, diabetes, hyperlipidemia, coronary heart disease, depression, stroke, cancer, and premature mortality (CDC, 2009b). The annual U.S. health cost associated with obesity approximates $\$ 147$ billion (Finkelstein, Trogdon, Cohen, \& Dietz, 2009).

Health experts generally recognize that obtaining recommended levels of physical activity can reduce the risk of obesity and obesity-related diseases (U.S. Department of Health and Human Services [USDHHS], 1996). The USDHHS provides three categories of physical activity guidelines for children and adolescents (age 6-17 years), adults (age 18-64 years), and older adults (age 65+ years) (USDHHS, 2008). Children and adolescents should engage in 60 or more minutes of physical activity daily. Healthy adults (i.e., those without disabilities or chronic disease) and elderly (over the age of 65) individuals are recommended to obtain at least 150 minutes of moderate intensity or 75 minutes of vigorous intensity physical activity per week, but to increase the health benefits it is encouraged to be physically active 300 minutes per week (USDHHS, 2008). Benefits related to obtaining prescribed levels of physical activity include managing weight; reducing risk for cardiovascular disease, type-2 
diabetes, stroke, and some cancers; strengthening bones and muscle tissues; reducing high blood pressure and pain associated with arthritis; improving mental health and mood; and increasing life expectancy (CDC, 2011).

Unfortunately, despite the USDHHS guidelines and benefits of physical activity, more than $60 \%$ of adults in the United States do not achieve the recommended amount of physical activity, while about $25 \%$ of all adults are not active at all (CDC, 2001; USDHHS, 1996). Accelerometer, a measurement of minute-by-minute steps and activity bouts, data collected in the U.S. identified that $49 \%$ of boys and $35 \%$ of girls aged 6-11 years met the recommended levels of physical activity; however, this dropped to $12 \%$ for boys and 3\% for girls by age 12-15 (Troiano et al., 2008). Generally, health disparities linked with physical activity disproportionately affect minorities; with many of these groups being less physically active than their White counterparts (USDHHS, 1996). Hispanics, for example, reported the highest levels of no leisure-time physical activity (34.6\%) (i.e., any physical activities or exercises such as running, calisthenics, golf, gardening, or walking), as compared to non-Hispanic Whites (22.2\%) and African-Americans (31.9\%) (CDC, 2008). Income has also been shown to influence the likelihood of meeting physical activity recommendations; more specifically, suburban, higher income residents were more than two times more likely to meet recommendations as rural, lower income residents (Parks, Housemannn \& Brownson, 2003). These disparities are widely recognized in the research although there is still a need to better identify whether factors in the built environment contribute to disparities in physical activity and obesity. Some of these socioeconomic and built environment factors have been identified and will be discussed below.

\section{Social Determinants of Health}

There is increased evidence indicating that a broad range of social, political, and economic factors have an effect on health. Social determinants of health are defined as the conditions in which people are born, grow, live, work, and age, in conjunction with the health care system that is available to 
them (World Health Organization [WHO], 2008), and these determinants are largely responsible for a wave of preventable health inequities. A movement to better understand the social determinants of health has come to the forefront of eliminating health disparities and should be utilized to tackle the obesity epidemic.

In the United States, increased health conversation by public health researchers and practitioners has led to heightened information about the social determinants of health although scholars still differ on which factors to include. Early research regarding the social factors focused mainly on family income, social class, and general health, though lists have expanded and now include additional social, economic, and political factors in correspondence with a wide range of natural (e.g. clean air, water, and soil) and built environment (e.g., land use patterns and community design) aspects (Halfon, Larson, \& Russ, 2010). With this expanded definition came a push by health organizations to better incorporate the social determinants of health in their action plans. For example, the WHO Commission on Social Determinants of Health (CSDH) (2008) indicated that understanding how social factors affect health is important because:

The global context affects how societies prosper through its impact on international relations and domestic norms and policies. These in turn shape the way society, both at national and local level, organizes its affairs, giving rise to forms of social position and hierarchy, whereby populations are organized according to income, education, occupation, gender, race/ethnicity and other factors. Communities and cities that ensure access to basic goods, that are socially cohesive, that are designed to promote good physical and psychological well-being and that are protective of the natural environment are essential for health equity.

Healthy People 2020 has also taken steps to integrate social determinants of health to solve ongoing health disparities. While no specific objectives have been developed, the overall goal of the new section 
states that Healthy People 2020 seeks to, "create social and physical environments that promote good health for all" (USDHHS, 2010). This goal supports the idea that all individuals deserve an equal opportunity to make healthy choices and that advances in health care and improvements in society (e.g., education, childcare, housing, law, and community development) will ensure that everyone has those same opportunities.

Public interest concerning the importance of social determinants is also growing. Based on a national telephone survey, Robert \& Booske (2011) found that the physical environment $(70 \%$ of respondents), income (44\%), and race/ethnicity (22\%) were all social factors that U.S. adults found important for health. When referring to income, Burris (2011) suggests that the relationship between income and health is simple: the greater the family income, the longer the life; this creates a social gradient where, in general, the lower an individual's socioeconomic position, the worse their health. Kawachi \& Kennedy (1997) added that income inequality has spillover effects and is positively associated with crime and violence, while decreasing productivity, economic growth, chances to prosper, and cause further social injustices. Health disparities negatively affect many racial and ethnic minorities, with many of these groups having inferior health statuses, decreased access to health care, and low levels of health information compared to their non-minority counterparts (Richardson \& Norris, 2010; Song et al., 2011; Viswanath \& Ackerson, 2011). While these racial and ethnic issues have been established in the literature, few studies have looked specifically at how origin of birth, more specifically being foreign-born, affects health. More studies should look at this factor as many foreignborn individuals are among these racial and ethnic minorities. With that said, the health and academic communities need to adopt a framework for better social inclusion in order to better guide the implementation of policies and practices that reduce health inequities related to income, race, gender, ethnicity, geographic location, age, ability, and sexual orientation.

A social determinant approach suggests that improving income, housing, transport, employment, 
education, social support, and health services is central to improving health. More specifically, understanding these social factors can be useful in researching and decreasing disparities in obesity and physical activity. Studying the availability, accessibility, proximity, and quality of public facilities (i.e., parks and physical activity areas) within the context of social determinants can further aid in diminishing these disparities. Enhanced understanding of social determinants and physical activity will also increase the appreciation for the role parks play in promoting health (Kaczynski, \& Havitz, 2009). Increasing awareness about the social determinants of health and the importance of the publically available physical activity areas can aid in mobilizing less advantaged groups to eliminate health inequities related to physical activity and obesity; undertaking these issues is key to improving the overall health status, establishing successful health care reform, and guarantying equality for all.

\section{The Built EnVIronment And PARKS}

The obesity epidemic is a complex issue and cannot be attributed to a single cause; therefore no simple solution is likely. Improvements may come, however, from one area of study that has grown in obesity research: the built environment. This factor is important to study because it has been shown that the area where individuals live and/or how close they live to resources can impact their health (Aileen, Kelly, Amy, Sara, \& Daniel, 2007; Giles-Corti, Kelty, Zubrick, \& Villanueva, 2009; Samimi \& Mohammadian, 2010). The built environment includes all man-made physical spaces that individuals are exposed to such as, cities, city centers, neighborhoods, individual offices, grocery stores, and parks (Tiwari et al., 2010). Much of the world's population now lives its life within urbanized areas with complex built environments. It is also known that the social, economic, and physical make-up of the built environment may pose opportunities to improve health equity, and when properly constructed, the built environment can provide financial security and adequate material resources. A well-built physical environment and high-quality social conditions can also empower an individual and community to overcome health inequities and pursue a more enjoyable life (Tannerfeldt \& Ljung, 2006). 
The built environment has been extensively shown to be linked to physical activity (Diez Roux \& Mair, 2010; Lovasi et al., 2011; Rodríguez et al., 2012). Research regarding the built environment has included walkability, food environments, and recreational spaces (Bauman \& Bull, 2007; Frank \& Engelke, 2005; Ford \& Dzewaltowski, 2005; Handy, Xinyu, \& Mokhtarian, 2006; Lovasi, Moudon, \& Pearson, 2008; Saelens \& Handy, 2008). Public parks are a key component of the built environment and play an invaluable role in promoting health (i.e., increased physical activity) although certain park characteristics can affect park usage differently. While understanding these characteristics is important in promoting physical activity at public facilities, lack of policy and funds has also impeded the creation of more physically active-friendly communities. In order to combat this, Healthy People 2020 aimed to increase provisions for legislative policies that back the building of communities that enhance access and availability to physical activity opportunities (USDHHS, 2010); in the hopes of improving health, fitness, and quality of life through daily physical activity. This effort will help promote the construction of desirable, publicly available facilities and will increasingly aid neighborhoods to become places to live and be physically active. While there is a push for building more physically active neighborhoods, issues such as proximity, accessibility, and lack of features (i.e., facilities and amenities) still affect park use and will be discussed below.

\section{Parks And Physical ACtivity}

Parks and recreational facilities are key components of the built environment that can influence physical activity (Bedimo-Rung, Mowen, \& Cohen, 2005; Humpel, Owen, \& Leslie, 2002; Kaczynski \& Henderson, 2007; Moody et al., 2004). Parks offer physical activity opportunities, are present in most communities, serve a large population, and are available to individuals at minimal or no cost (Godbey, Caldwell, Floyd, \& Payne, 2005; Moody et al., 2004), making them desirable activity sites. A number of observational studies approximated that $40 \%$ of park use can be classified as physically active (Cohen et al., 2007; Floyd, Spengler, Maddock, Gobster, \& Suau, 2008). Addy et al, (2004) found that individuals 
aged 18 years and over who used recreational facilities such as parks were significantly more likely to be active. Another study (Deshpande, Baker, Lovegreen, \& Brownson, 2005) identified that use of parks considerably increased the odds of engaging in 30+ minutes of physical activity 5 times a week $(\mathrm{OR}=$ $4.21,95 \% \mathrm{CI}=1.94,9.14$ ) and that shorter walking times to a park (i.e., proximity) was associated with more regular physical activity. Conversely, it has also been shown that there are not enough compelling correlations between parks and engaging in regular bouts of physical activity. Atkinson, Sallis, Saelens, Cain, \& Black (2005), for example, found that convenient recreational facilities were not significantly related to moderate, vigorous, or total physical activity; these findings were based on self-reports. While some of the research on park use and physical activity may be conflicting, the overwhelming majority of research shows that parks are important environments for physical activity opportunities.

\section{Park Availability/Accessibility and Physical Activity}

In general, research has found positive associations between increased physical activity and park availability and accessibility (Henderson, 2007; Sallis et al., 2006). Availability and accessibility to parks and their perspective features have been shown to increase an individual's chances of becoming physically active (Sallis et al., 2006), while also reducing sedentary activity time (Carson, Kuhle, Spence, \& Veugelers, 2010). Brownson, Baker, Housemann, Brennan, \& Bacak (2001) concluded that having access to physical activity environments, such as parks, increased the odds $(\mathrm{OR}=1.95,95 \%$ $\mathrm{CI}=1.52,2.52)$ of U.S. adults meeting physical activity recommendations. Likewise, Blanchard et al., (2005) identified that availability of recreational facilities was also a significant predictor of engaging in physical activity in normal and overweight, but not obese, adults. Youth populations are also influenced by increased park availability and accessibility. Among 10-12 year olds, perception of no nearby parks was related to fewer walking and cycling trips (Timperio, Crawford, Telford, \& Salmon, 2004). Using accelerometer data, Roemmich et al., (2006) concluded that neighborhoods with a greater proportion of park area were associated with increased physical activity among children (boys and girls aged 4-7 
years). Similarly, Cohen et al.'s (2006) all-adolescent-girl investigation used accelerometer data to identify that the number of parks within one mile of participants' homes was significantly related to total moderate-to-vigorous physical activity. Boone-Heinonen, Casanova, Richardson, \& Gordon-Larsen (2010) similarly identified that young girls who had availability of major or neighborhood parks was associated with higher participation in active sports. Increased access to parks has also been related to increased physical activity in boys (Roemmich, Epstein, Raja, \& Yin, 2007). Seniors (65-94 years old) who lived in neighborhoods with greater access to recreational physical activity facilities had fewer declines in walking activity over a year time period (Li, Fisher, \& Brownson, 2005). In summary, availability of recreational facilities has not only been shown to increase park use, but also to increase park use for physical activity.

\section{Park Proximity and Physical Activity}

Studies observing park proximity suggest that individuals who live closer to recreational spaces and parks are more physically active overall (Mota, Almeida, Snatos, \& Ribeiro, 2005; Kaczynski et al., 2009; Sallis, \& Glanz, 2009). Ball, Bauman, Leslie, \& Owen (2001) found that respondents with low and moderate convenience of physical activity facilities were significantly less likely to walk for exercise than those reporting high convenience of facilities. A convenience tally score (i.e., 5-minute drive from work or home to facilities) study conducted in Belgium, indicated that convenience of recreational facilities was significantly related to the amount of vigorous activity in adults (De Bourdeaudhuij, Sallis, \& Saelens, 2003). A longitudinal cohort study in children found an inverse relationship between parks acres within 500 meters of a child's home and the child's BMI at age 18 (Wolch et al., 2011). Among seventh grade school boys, distance to the nearest open play area was inversely and significantly related to bouts per week of outdoor physical activity (Gomez, Johnson, Selva, \& Sallis, 2004). Likewise, Cohen et al. (2006) identified that girls living near parks engaged in more moderate to vigorous physical activity than girls with fewer parks in close proximity. A study 
looking at persons 50 years or older, found that surveyed individuals had higher physical activity scores when reporting the presence of facilities (e.g., walking trails, biking trails, parks, swimming pool) within a 5 minute walk or drive (Chad et al., 2005). King and associates (2003) also found that, among older women, having a park within a 20-minute walking distance significantly increased participants overall steps per day. Much of the data supporting park proximity is age focused, but overall, close proximity of park space has been found to be a predictor of physical activity and indicative to increased physical activity.

\section{Park Features/Characteristics and Physical Activity}

Most parks can be classified as publically available areas that provide access to various features and possess characteristics that can promote physical activity. Park features include facilities (e.g., play grounds, basketball courts, sports fields, tennis courts), amenities (e.g., trash cans, picnic tables, grills, benches), and aesthetics (e.g., presence of flower garden or statue, maintenance). Park characteristics incorporate the quality and safety concerns of the park and surrounding neighborhood. Giles-Corti et al. (2005) pointed out that the number of attributes at public open spaces, such as parks, has been shown to be directly associated with the number of people who visit these sites. Additionally, it has been shown that the presence of certain park facilities and amenities can be key in encouraging park use for physical activity (Kaczynski, Potwarka, \& Saelens, 2008). The same study indicated that the number of park features was more important than the park's size or proximity for predicting park use for physical activity, with park facilities being fairly more important than amenities (trails had the highest association of the park being used for physical activity). Kaczynski \& Havitz (2009) also examined the relationship between park features and park use and determined that certain facilities and amenities are more likely to encourage physically activity. Their results were mixed, identifying an increased likelihood of using parks for physical activity with five facilities (unpaved trail, meadow, water area, basketball court, and soccer field) and six amenities (restroom, historical/educational feature, landscaping, bike rack, parking 
lot, and a roadway through the park), but also found a negative association with baseball diamonds and park use. A study focusing on healthy weight status among children identified that availability of certain park facilities (e.g., playgrounds and water facilities) can play a more important role in promoting physical activity than availability of park space (Potwarka, Kaczynski, \& Flack, 2008). Among young boys, Timpiero et al. (2008) found that certain park features, specifically the existence of playgrounds, increased their weekend moderate-to-vigorous physical activity; although the same study also concluded that the number of recreational facilities was inversely associated with younger girls' after school and weekend moderate-to-vigorous physical activity. An investigation of environmental factors and recreational facilities among African-American adolescents found that low-cost, well-maintained facilities, close proximity, presence of other active children, and safety are important indicators of park use (Ries et al., 2008). Significant characteristics that were also found to contribute to park use and physical activity in youth populations were active recreation facilities (i.e., playgrounds, basketball courts), sports programs, and the presence of natural features (Loukaitou-Sideris \& Sideris, 2010). Walking trails are another park facility that has been shown to be a key in encouraging physical activity at parks among various age groups (Kaczynski, Potwarka, \& Saelens, 2008; Wilhelm Stanis, Schneider, Shinew, Chavez, \& Vogel, 2009), with more aesthetically pleasing trails leading to increased walking behaviors (Wilcox, Castro, King, Houseman, \& Brownson, 2000).

Park quality, specifically the condition of the facilities and amenities, is another park characteristic that can also influence a park's utilization (Leslie, Cerin, \& Kremer, 2010; Perry, Saelens, \& Thompson, 2010). A study looking at children and park use found that one of the most significant factors determining park use was proper maintenance and cleanliness (Loukaitou-Sideris et al., 2010). Furthermore, a study conducted in North Carolina that looked at perceptions of public parks identified that recreational directors believe that the quality of facilities and equipment is one of the most significant barriers to physical activity in their communities (Bocarro et al., 2009). Using focus group 
based research Blahna \& Black (1992) found that poor park quality was a barrier to use in Chicago, IL. Aesthetically pleasing features such as gardens, ponds/lakes, trees, and shrubbery are important park characteristics for increasing physical activity (Corti, Donovan, \& Holman, 1996), while graffiti, vandalism, litter, and dog feces discouraged park use (Corti, Donovan, \& Holman, 1996; Day, 2008). While there has been limited research conducted on the relationship between park condition and park usage, studies have shown that certain park characteristics increase physical activity at parks. Further identification of which characteristics increase park use needs to be addressed, specifically in areas with low abundance of high quality resources.

\section{Parks, Social Determinants of Health, And Disparities}

\section{Park Availability/Accessibility}

Research has identified disparities in park availability and accessibility among certain populations. More specifically, the research suggests that lower socioeconomic status and minority populations have decreased availability and accessibility to physical activity areas and recreational facilities compared to populations of higher socioeconomic status and lower minority groups (Moore, Diez-Roux, Evenson, McGinn, \& Brines, 2008; Wolch et al., 2005). Among minority populations, Moore and associates (2008) identified that Black and Hispanic neighborhoods were more than three and eight times, respectively, less likely to have recreational facilities when matched to White neighborhoods. The same study also determined that low-income neighborhoods were almost five times more likely not to have facilities compared to neighborhoods of higher income. Gordon-Larsen, Nelson, Page, \& Popkin (2006) also concluded that lower socioeconomic and high minority block groups had reduced availability to recreational facilities. This was based on the authors' findings that high socioeconomic block groups had significantly greater access to at least one facility compared to low socioeconomic and high minority block groups; in addition, the study also revealed that increased number of facilities was related to decreases in weight and increases in physical activity. 
Accessibility to parks was also found to differ across low socioeconomic and minority populations. A study (Cutts, Darby, Boone, \& Brewis, 2009) conducted in Phoenix, AZ, looked at park accessibility within youth populations and found that the areas with the highest minority youth population had the lowest park access and least walkable communities. While also examining neighborhoods with a high percent of racial minority residents, Powell et al. (2006) found that facilities (both public and commercial) were unevenly distributed among higher minority neighborhoods versus those of lower minority. Estabrooks and colleagues (2003) concluded that lower socioeconomic neighborhoods were less likely to have the advantages of environments that promote physical activity; this was based on their finding that low socioeconomic status neighborhoods had less accessibility to parks and lower recreational facility utilization than high socioeconomic areas. Using ImpacTeen and Census Bureau data, Powell, Slater, \& Chaloupka (2004) also revealed that high poverty communities have less access to places where they can be physically active while communities with higher median income brackets have more of these features.

\section{Park Facilities and Amenities}

The number of park facilities and amenities are also important predictors for promoting park utilization, although mounting research shows that park characteristics also differ between low/high income and low/high minority areas. For example, Powell et. al. (2004) listed sports facilities, parks, green spaces, and bike paths were significantly less likely to be available in low socioeconomic status neighborhoods versus high socioeconomic areas; the authors added that there needs to be increased support for strategies that target interventions in these areas. Moore and associates (2008) concluded that there is not equal distribution of recreational facilities; more specifically, the authors found that lowincome neighborhoods were 4.5 times less likely to have facilities than high-income areas. The same study also indicated that Black minority neighborhoods were more than three times more likely not to have recreational facilities than White neighborhoods, while Hispanic minority neighborhoods were 
more than eight times more likely not to have those facilities. While examining the relationship between neighborhood socio-economic status and features of public open spaces (POS) in Australia, Crawford et al. (2008) identified that POS in the high socioeconomic neighborhoods were more abundant, had more amenities (e.g., picnic tables and drink fountains), and an increased number of features (e.g., trees that provide shade, water features, walking and cycling paths, lighting, signage regarding dog access and signage restricting other activities) that are conducive to children's physical activity, compared to those of lower socioeconomic neighborhoods.

\section{Park Quality}

Beyond park availability/accessibility and the number of facilities and amenities a park may have, the quality and maintenance of park sites can also affect if that park is used for physical activity or not. Few studies investigate the relationship between park quality/maintenance, socioeconomic status, race, and physical activity rates; however, a study of 28 parks in Montreal, Canada, found that park quality was lower within poor health areas (i.e., low life expectancy and high incidence of disease) compared to neighborhoods with the highest health status. Based on the variations they found in park quality (e.g., concentration of incivilities at park, quality of facilities and amenities, and safety) and neighborhood health status, the authors concluded that park quality is an important factor in determining park use and that closing the park quality gap between the areas can aid in promoting health (Coen \& Ross, 2006). While looking at childhood obesity among disadvantaged and minority children, Kumanyika \& Grier (2006) identified derelict, low quality parks as a barrier to physical activity, possibly contributing to the current disparities in obesity and physical activity among low-income/high minority adolescents. A study in Chicago, IL, described that lower-income and racial/ethnic minority neighborhoods had lower quality recreational areas; more specifically, they had poor vegetation and low levels of maintenance compared to higher-income and non-minority neighborhoods (Gobster, 1998). Finally, Joassart-Marcelli (2010) documented that funding for parks and recreation in Los Angeles, CA 
was highly uneven, generally favoring middle-income communities and suppressed in suburbs with large minority and low-income populations.

\section{GAPS IN THE LITERATURE}

While a number of studies show that disparities in park availability and accessibility exist among low income and minority populations, a significant amount of research provided mixed results. For example, while looking at availability of public open space (POS) among socioeconomic disadvantaged neighborhoods, Timperio, Ball, Salmon, Roberts, \& Crawford (2007) concluded that there were no differences in the number or total area physical activity facilities across neighborhood socioeconomic quintiles, once neighborhood population and geographic areas were controlled. Utilizing the Physical Activity Resource Assessment (PARA) instrument, a brief, one-page instrument used to assess the features, amenities, quality and incivilities of a variety of physical activity resources, another study revealed that the number of physical activity facilities were similar in low income/high minority neighborhoods and high income/low minority neighborhoods (Lee, Booth, Reese-Smith, Regan, \& Howard, 2005). Abercrombie and colleagues (2008) found that the number and size of public parks across their Maryland study area did not reveal significant disparities according to income or racial groups. Using a cross-sectional survey stratified by socioeconomic status, Giles-Corti \& Donovan (2002) discovered that respondents in low socioeconomic areas generally had greater access to recreational facilities compared those in high socioeconomic areas, but they were less likely to use them. Crawford et al. (2008) used the Children Living in Active Neighbourhoods (CLAN) Study and the Socio-Economic Index for Areas Index (SEIFA) of Relative Socio-economic Advantage/Disadvantage to study the number of facilities by socioeconomic status and found that there were no differences in the number of playgrounds or the number of recreation facilities (e.g. sports courts, athletic tracks, skateboarding facility, and swimming pool) across dissimilar socioeconomic neighborhoods. Using census tracts, Estabrooks et al. (2003) found that different socioeconomic neighborhoods did not differ 
in the number of physical activity facilities; however, while the number of pay-for-use parks, sport facilities, fitness clubs, community centers, and walking/biking trails did not differ by socioeconomic status, it was noted that there were fewer free-for-use resources in low-SES neighborhoods. Utilizing questionnaire data on the perception of availability to public recreational facilities, a study found that respondents in lower socioeconomic status areas reported less availability of public recreational facilities than high socioeconomic status areas; however, the perception of less availability was not validated by GIS data (Wilson, Kirtland, Ainsworth, \& Addy, 2004). Finally, in a 2004 study, Powell et al. found that while U.S. communities with high percentages of African-Americans had less availability to sports areas, parks, green spaces, public pools, and beaches, communities with a high percentage of Hispanic had higher numbers of all physical activity facilities, contradicting previous studies.

\section{Statement of the Problem}

To summarize, it has been shown that recreational facilities and their availability, accessibility, proximity, facilities, amenities, and quality can all be strong indicators for physical activity and promoting better overall health; however, there are also still some inconsistencies in the literature. Further research is needed in these areas of study, with a focus at the local level, so that distribution of resources (i.e., government funds, high quality recreational facilities and amenities) can be equally satisfied across the diverse sprawl of many U.S. cities. 


\section{Chapter 2: Purpose of Study}

Research has reported that low socioeconomic status neighborhoods with high concentrations of low-income individuals and ethnic minorities have reduced availability/access to parks with fewer high quality amenities/features as compared to more affluent, predominately White neighborhoods. To date, the relationship between neighborhood socioeconomic and sociodemographic composition with park availability, features (i.e., park facilities, amenities, and aesthetic features), and characteristics (i.e., park quality concerns and neighborhood safety concerns) has not been examined in a border environment with a majority Hispanic population. Studying these relationships in this environment can ultimately provide insight into the relationship between disparities in the built environment, physical activity, and obesity. The primary purpose of this study is to examine any disparities in park availability, features, and characteristics among socioeconomically and demographically diverse neighborhoods (i.e., census tracts) along a U.S. border community. The study will specifically address the following research aims.

\footnotetext{
AIMS

The overall aim of this study is to describe park availability, park features, and park characteristics, and determine their association with two social determinants of health (i.e., median household income and percent foreign-born) in a predominately Hispanic border community. In order to investigate this, three specific aims were created. The specific aims of the study are discussed below.

Specific Aim 1: Measure the availability of parks within City of El Paso, Texas at the neighborhood level.

Specific Aim 2: Systematically assess park features of City of El Paso parks.

Specific Aim 3: Determine if there is an association between park availability, features (e.g., facilities, amenities, and aesthetic features) and characteristics e.g., (park quality concerns and neighborhood safety concerns) among median household income census and percent foreignborn tertiles.
} 


\section{HYPOTHESES}

1. Park availability (i.e., number of parks) will differ by median household income and percent foreign-born tertiles.

2. There will be a difference in the number of park features (i.e., park facilities, amenities, and aesthetic features) by median household income and percent foreign-born tertiles.

3. There will be a difference in the number of park characteristics (i.e., quality/safety concerns of the park and surrounding neighborhood) by median household income and percent foreign-born tertiles.

This study will use a newly developed park audit tool to systematically assess park availability, park features (i.e., park facilities, amenities, and aesthetic features), and park characteristics (i.e., quality/safety concerns of the park and surrounding neighborhood) by median household income and percent foreign-born tertiles in the predominately Hispanic, Border City of El Paso, Texas. By observing and understanding any disparities, this project will aid policy makers, city park officials, and community members to develop better city plans. The desired outcome is equal distribution of physical activity environments across the city and to promote participation in physical activity and increase the healthpromoting potential of parks. 


\section{Chapter 3: Methods and Materials}

\section{STUDY DESIGN}

An observational, cross-sectional, ecological study design was used to examine if there were differences in park availability, park features, and park characteristics among median household income and percent foreign-born tertiles, in a U.S.-Mexico border urban environment. Three components (sources of data) were utilized in the following study. The first component was the American Community Survey, which was used to obtain demographic and socioeconomic information for census tracts within the City of El Paso, Texas. Geographic Informational System (GIS) maps (layers), provided by the City of El Paso were the second source of data and were used to determine park availability (i.e., mean number of parks) per census tract. Finally, the Community Park Audit Tool (CPAT) (Appendix 1) was selected to gather park information and assess the number of park features (e.g., park facilities, amenities, and aesthetic features) and characteristics (e.g., quality/safety concerns of the park and surrounding neighborhood). Descriptions and further information on how each source was obtained will be discussed in the data collection section.

\section{STUDY SeTting}

\section{City of El Paso, Texas}

The following study was a research project conducted between August 2010, and April 2012. The study site was El Paso, Texas, a city located in West Texas and the county seat of El Paso County. The city is situated on the U.S.-Mexico border and part of a major metropolitan area that includes several outlying cities (e.g., Socorro, Canutillo, Fabens, Horizon, Clint, Van Horn, and Las Cruces, NM) and Ciudad Juarez, a Mexican city located directly to the south of El Paso. The El Paso-Juarez-Las Cruces Metropolitan area has more than 2.3 million inhabitants and is the second largest bi-national area along the 2,000 mile U.S.-Mexico border. The present study only focused on the City of El Paso, which spans 255 square miles with a population just over 600,000 individuals (U.S. Census Bureau, 2000b). 
The City of El Paso is characterized by a diverse demographic and socioeconomic profile. The racial/ethnic make-up of the city is predominately of Hispanic origin (80.0\%) with non-Hispanic Whites $(15.0 \%)$ and Black or African-Americans (2.6\%) making up a large portion of the remaining total population. The city has a high proportion of foreign-born residents (25.7\%), most of which are Mexican immigrants. According to 2000 census data, there were a total of 202,225 households, with a median household income of $\$ 36,147$; the civilian labor force unemployment rate was $7.2 \%$ (U.S. Census Bureau, 2000b).

\section{City of El Paso's Parks}

The El Paso Parks and Recreation Department (EPPRD) listed a total of 175 park sites containing approximately 2,612 acres of parkland and natural areas within the City of El Paso. The park total includes all city parks in the planning area, excluding Franklin Mountains State Park and Chamizal National Memorial Park. The overall existing ratio of park acres to population is approximately 3.5 acres of park land for every 1000 residents, excluding Rio Bosque and McKellingon Canyon, which are large natural or special purpose parks. Parks are classified into five regions (Central, Northwest, East, Northeast, and Mission Valley) and six types (pocket, neighborhood, community, linear, special use, open space, or nature parks). Finally, there was a wide-range of available features among City of El Paso parks, which include, but are not limited to, playgrounds, pools, basketball courts, baseball diamonds, picnic shelters, tennis courts, trials, recreational/senior centers, and ball fields (EPPRD, 2006).

\section{STUdy SAMPLE}

The first sampling unit was City of El Paso, TX, census tracts. Census tracts are small, relatively permanent statistical subdivisions of a county or equivalent area that are maintained by local participants prior to each decennial census as part of the Census Bureau's Participant Statistical Areas Program. The primary purpose of census tracts is to provide a stable set of geographic units for the presentation of statistical data (i.e., statistical comparisons) over a long period of time, typically between each census 
period. They are designed to be homogeneous in nature; specifically with respect to population characteristics, economic status, and living conditions. Census tracts generally have a population size between 1,200 and 8,000 people, are contiguous, and widely vary in spatial size, depending on the population density of the area. Between census periods, tracts do not change; however, physical changes in street patterns caused by highway construction, new development, and other factors may require occasional revisions (U.S. Census Bureau, 2000a). Additionally, census tracts occasionally are split due to large population growth, or combined as a result of substantial population decline. United States Census tract boundaries commonly follow visible and identifiable features such as streets and legal precincts and do not cross county lines. Census tract numbers are identified by up to four-digit integer numbers and may have an optional two-digit suffix; census tract codes consist of six digits with an implied decimal between the fourth and fifth digit (U.S. Census Bureau, 2000a). A list of the current census tracts within city limits was provided by the City of El Paso (2004), as well as the census tract GIS layer. At the time of the study, there were 126 census tracts within El Paso County, although for the purpose of this study only census tracts identified within the City of El Paso were included; 14 were excluded.

A total of 175 park sites are listed by the El Paso Parks and Recreation Department (EPPRD) master plan (EPPRD, 2006). Only fully developed pocket, neighborhood, and community parks within the City of El Paso were audited for this study (see Appendix 2 for park descriptions). Twenty-one linear, special-use, open space, nature, undeveloped, and sites under renovation were excluded from the study because these park types are typically only open land and have few additional features or facilities. Parks were ultimately included in the study after an in-person, on-site, CPAT audit concluded that the park site was useable for physical activity/recreation (i.e., not under renovation or construction) and publically accessible. Ten parks were also excluded because they were either closed for maintenance or renovations. Playgrounds and other recreational facilities at schools were not considered in the study 
because these sites are not publically available and typically closed during after-school hours. The final number of parks included in the study was 144 (see Appendix 3 for a complete listing of the number of parks audited by type and region).

\section{Data Collection}

The American Community Survey (ACS) was used to obtain median household income and percent foreign-born information at the census tract level. The ACS is an ongoing statistical survey conducted by the U.S. Census Bureau, which provides communities with current information useful for planning investments and services; more specifically, the survey helps determine how more than $\$ 400$ billion in federal and states funds will be distributed each year. Conducted every year and sent to approximately three million addresses a year, the survey asks various demographic, economic, social, and housing information such as age, sex, race/ethnic background, place of birth, family status, income, benefits, health insurance, education, veteran status, and disabilities; all these are used to decide on funding for everything from school lunch programs to new hospitals. Other than the decennial, the ACS is the second largest survey conducted by the U.S. Census (ACS, 2011a).

This study used the ACS website to download two key variables, specifically median household income and percent foreign-born, from the 2005-2009 five-year estimates. The ACS data is grouped into one, three, and five year estimates; compared with the one-year and three-year estimates, the five-year estimates use 60 months of data, provides the largest sample size, is the most reliable, covers the largest area, but is the least current (ACS, 2011b). Additionally, the five-year estimates are the only of the three estimates that analyses geographical areas as small as census tracts, which is why they were selected for this study.

Two Geographical Information System (GIS) shape files (aka layers) provided by the City of El Paso were used to identify all parks and census tracts within the City of El Paso. Geographic Information Systems are computerized systems that are used for the storage, retrieval, manipulation, analysis, and display 
of geographically referenced data (Kurland \& Wilpen, 2006); in the current study, City of El Paso parks and census tracts were the geographic reference. Using GIS (v. 9.3, Redlands, CA) the two layers (i.e., sampled parks and census tracts) were stacked on top of each other; assigning parks to census tracts and providing a count of parks per census tract. This step provided the park availability variable.

Data on park features (i.e., park facilities, amenities, and aesthetic features) and characteristics (i.e., quality/safety concerns of the park and surrounding neighborhood) were collected using the Community Park Audit Tool (CPAT). The CPAT is a user-friendly, newly developed park audit tool that was developed in conjunction with researchers and community stakeholders to reliably assess a park's potential to promote physical activity. The CPAT uses standardized questions and researcher observations to measure park features and characteristics; more specifically, the tool provides a reliable means of auditing parks for their potential to promote physical activity (Kaczynski, Wilhelm Stanis, \& Besenyi, 2012). The tool was part of an Active Living Research project funded through the Robert Wood Johnson Foundation. The CPAT is six pages long (30 questions) and contains four sections; the four titled sections include park information, access and surrounding neighborhood, park activity areas, and park quality. The tool was chosen for this study because it was user-friendly, constructed with and supported by community stakeholders, covered a wide-range of questions, and had a high inter-rater reliability for a majority of the questions (Kaczynski et al., 2012).

Park audits were conducted on multiple days between the time period of September 2010 and March 2011, with audits lasting about 15-20 minutes. Basically, the process was as follows: the auditor would arrive at the site and quickly walk throughout; from there, the auditor would then re-walk the park and make note of any observations using the check boxes and comment space on the CPAT. Once the audit was completed, the end-time was estimated and the auditor would move on to the next site. This was done for all parks in the sample. 
The primary researcher conducted on-site audits for a total of 154 parks within the City of El Paso, Texas; assigned parks were visited, observations made, and data recorded using the CPAT. The researcher received training on how to utilize the CPAT during a workshop conducted by Dr. Andrew Kaczynski of the Arnold School of Public Health at the University of South Carolina in September 2010. The audit tool and guidebook for the CPAT were developed by Dr. Andrew Kaczynski, Dr. Sonja Stanis of the University of Missouri, Department of Parks, Recreation, and Tourism, and Gina Besenyi of Kansas State University, Department of Kinesiology, Physical Activity and Public Health Laboratory.

\section{MEASURES}

\section{Social Determinants of Health}

There were two independent variables for the current study. The first independent variable was median household income; perhaps the single most widely used measure of income in the census. The median is defined as the level of household income at which half of households earn more and half earn less; it is based on all households, including families, individuals living alone, and other household types. Median household income was used instead of mean household income because income is typically not distributed normally (non-parametric), thus median and interquartile range better represent the central distribution of such variables. Median is also not influenced by extreme outliers making it more suitable to use for income than the mean.

The U.S. Census Bureau calculates median household income by summing various financial variables within the last year of the survey; these variables include wages, salary, commissions, bonuses, or tips from all jobs, self-employment income from own nonfarm businesses or farm businesses, including proprietorships and partnerships, interest, dividends, net rental income, royalty income, or income from estates and trusts, social security or railroad retirement, supplemental security income (SSI), any public assistance or welfare payments from the state or local welfare office, retirement, survivor, or disability pensions, any other sources of income received regularly such as Veterans' (VA) 
payments, unemployment compensation, and child support or alimony (U.S. Census Bureau, 2011a). Moreover, the U.S. Census defines household as all U.S. residents who live in housing units such as single-family homes, townhouses, apartments, and mobile homes (U.S. Census Bureau, 2011b). The ACS provides median household income in a 2009 inflation-adjusted dollar figure for each census tract.

The second ACS based independent variable of the study was percent foreign-born, which was also described at the census tract level. The U.S. Census Bureau defines the foreign-born individuals as anyone who was not a U.S. citizen or U.S. national at birth, whether they have become U.S. citizens through naturalization or not (ACS, 2010). Percent foreign-born was used instead of percent minority/ethnicity because the City of El Paso is approximately $80 \%$ Hispanic/Latino, thus percent minority/ethnicity would not have been an evocative component to analyze in the current study setting.

\section{Park Availability}

Park availability, or the number of sampled parks located in each census tract, was the first dependent variable considered. A total of 144 parks were distributed among (within) 112 census tracts, but only 72 census tracts contained parks, 40 census tracts did not. Parks were considered within the census tract if any portion of the park intersected any portion of the census tract (Abercrombie et al., 2008; Krieger et al. 2003; Vaughn, 2011). The measure of park availability was based on a previous study, where Geographic Information Systems (GIS) was used to investigate the availability/accessibility (i.e., summation) to playgrounds per unit area (i.e., specified radius); in short, the more features there were the more available/accessible they were (Smoyer-Tomic, Hewko, \& Hodgson, 2004; Vaughn, 2011). For this study, the same method was applied but confined strictly to parks. To sum, park availability was a count of parks within each census tract; the more parks within the census tract the greater the availability. 


\section{Park Features and Park Characteristics}

Park features (i.e., park facilities, amenities, and aesthetic features) and characteristics (i.e., quality/safety concerns of the park and surrounding neighborhood) were obtained using the recently developed Community Park Audit Tool (CPAT) (Appendix 1). Three variables were defined under park features (i.e., park facilities, amenities, and aesthetic features) and two variables were considered characteristics (i.e., quality/safety concerns of the park and surrounding neighborhood); each of the five variables was looked at independently.

\section{ANALYSES}

\section{Data Management}

The ACS data was merged with the CPAT data by park number. ACS data for census tracts that had more than one park was repeated. All data was cleaned and missing values were coded as -9 . Census tracts identified outside the City of El Paso were subsetted out; parks that were visited, yet closed for renovation or undeveloped, were also subsetted out of the dataset. A total of 14 census tracts and 10 parks were excluded from the study. Fourteen variables (i.e., number of playgrounds, sports fields, baseball fields, swimming pools, splash pads, basketball courts, tennis courts, volleyball courts, trails, fitness stations, skate parks, dog parks, green spaces, and lakes) were recoded as categorical variables (i.e., $0=$ No and $1=$ Yes; if they had a facility or not) to provide descriptions for the number of park facilities at each park.

\section{Recoding Variables}

\section{Social Determinants of Health}

After the data was merged and subset appropriately, tertiles for median household income and percent foreign-born were constructed. The tertiles were an average of the income and percent foreignborn population per census tract; they were labeled as low, medium, and high income or foreign-born. The reason why tertiles were used in the current study was because the National Health and Nutrition 
Examination Survey (NHANES) used income groupings to compare various health outcomes in the past; in 2004, the five NHANES income groupings were the bottom quintile $(<\$ 22,367.00)$, second quintile (\$22,367.00-\$40,016.00), middle quintile $(\$ 40,016.00-\$ 60,895.00)$, fourth quintile $(\$ 60,896.00$ $\$ 92,886.00)$ and top quintile (>\$92,886.00) (U.S. Census Bureau, 2011c). While quintiles were used in the NHANES data, tertiles were used in the present study because recent park studies (Estabrooks et al., 2003; Powell et al., 2006; Vaughn, 2011) have utilized tertiles to analyze park measures with various socioeconomic characteristics. In this study, median household income cut points were used to create the three tertiles. The three cut points for each tertile were low $(<\$ 25,724.00)$, medium $(>\$ 25,724.00$ to $<$ $\$ 43,603.00)$, and high (> \$43,603.00). The number of parks in the low, medium, and high income tertiles were 47, 49, and 48, respectively. Similarly, percent foreign-born tertiles were created with the following cut points, low $(<22.2 \%)$, medium $(>22.2 \%$ to $<31.7 \%)$, and high $(>31.7 \%)$ foreign-born. The number of parks in the low, medium, and high percent foreign-born tertiles were 48, 49, and 47, respectively.

\section{Park Measures}

In total, six variables were constructed for the current study; five of which, were created by grouping (i.e., summing) certain items from the CPAT. This was based on a previous study which implemented the same process (Vaughan, 2011). The groupings of the five variables are discussed below.

\section{Park Facilities}

Park facilities came from section 3 of the CPAT, which audited 14 physical activity areas. The 14 park areas that were summed up to create the park facilities variable were playgrounds, sports fields, baseball fields, swimming pools, splash pads, basketball courts, tennis courts, volleyball courts, trails, fitness stations, skate parks, dog parks, green spaces, and lakes. 


\section{Park Amenities}

Section 2 and section 4 of the CPAT contained 20 items which were summed up to become the park amenities variable. These items included transit stops, car parking lot, sidewalks, curb cuts/ramps on the sidewalk, external trails, traffic signals, restrooms, drinking fountains, benches, picnic tables, picnic shelters, grills, trash cans, vending machines, baby changing station, rules posted about animals, animal waste bags, lights, park monitored, and emergency devices.

\section{Park Aesthetics Features}

The fourth variable, park aesthetic features, came from section 4 , question 30 , of the CPAT. Question 30 had 8 items, but only 7 were included in the study; those items that were summed to create the park aesthetic features variable included evidence of landscaping (e.g., flower beds, pruned bushes), artistic feature (e.g., statues, gazebos), historical or educational feature (e.g., monuments, educational signs), wooded area, trees throughout park, water features (e.g., lake, stream, pond), and meadow. The last item labeled "other" was excluded because the information from those variables was not specific (i.e., the auditor had to describe (write in) the response).

\section{Park Quality Concerns}

Section 4 , question $25,27,28$, and 29 were all used to sum the park quality concerns variable. The CPAT items used to create this variable were threatening behavior or persons (e.g. gangs, alcohol/drugs), roads through park, dangerous spots (e.g., abandoned building, pit/hole), graffiti, vandalism, excessive litter, excessive animal waste, excessive noise, and poor maintenance.

\section{Neighborhood Safety Concerns}

The last variable created was neighborhood safety concerns, which came from section 2 , question 11 (10 items from CPAT). This item looked at the presence of certain concerns from the neighborhood aspect, not the park aspect (which was addressed in the park quality concerns variable). The 10 items added together to create the neighborhood safety concerns variable were inadequate 
lighting, graffiti, vandalism, excessive litter, heavy traffic, excessive noise, vacant or unfavorable buildings, poorly maintained properties, lack of eyes on the street, and evidence of threatening persons or behavior.

\section{Statistical Analysis}

Descriptive statistics were provided for all demographic, socioeconomic, race/ethnicity, and park descriptions to further establish the setting of the study; categorical variables were presented using frequencies and percentages, while continuous variables were given as median and interquartile range (Q1 and Q3). Univariate analyses for park availability, park features (i.e., park facilities, amenities, and aesthetic features), and park characteristics (i.e., quality/safety concerns of the park and surrounding neighborhood) were conducted to provide descriptive statistics and to assess normality of continuous variables. Normality was determined by skewness between -1 and 1 and symmetric histograms.

Differences in mean number of park availability, features (i.e., park facilities, amenities, and aesthetic features), and characteristics (i.e., quality/safety concerns of the park and surrounding neighborhood) were analyzed by median household income and percent foreign-born tertiles (low, medium, and high); bivariate associations were tested with ANOVA (for normally distributed variables) and Kruskal-Wallis (for variables that were not distributed normally). All data were entered and analyzed using SPSS software (v. 19.0, SPSS Inc., Chicago, IL). Statistical tests were considered significant if the $\mathrm{p}<0.05$. For significant bivariate associations, pairwise comparisons were conducted to identify where the differences lied. Bonferroni and pairwise Kruskal-Wallis were used to conduct pairwise comparisons; tests were adjusted for multiple comparisons ( $\mathrm{p}$-value=0.05/3=0.0167). 


\section{Chapter 4: Results}

\section{DESCRIPTIVE STATISTICS}

\section{Characteristics of Study Area}

Descriptive statistics for the City of El Paso are provided in Appendix 4. The median total population per census tract was 5,934 $(\mathrm{Q} 1=4,182.5, \mathrm{Q} 3=8,358.0)$ and the median number of households per census tract was 2156.5 . The ratio of female to male was close to one $(53.0 \%$ to $47.1 \%)$ and median age was 32.2 years. The median household income for all census tracts was $\$ 33,800.50$ $(\mathrm{Q} 1=\$ 22,041.00, \mathrm{Q} 3=49,137.00)$, with a median civilian labor force unemployment rate of $7.1 \%$ $(\mathrm{Q} 1=5.1, \mathrm{Q} 3=8.8)$. More than a quarter of the population was foreign-born $(28.0 \%)$. Being a large urban center on the U.S.-Mexico border, El Paso has a high Hispanic population (87.0\%) most of which were of Mexican descent $(80.3 \%)$.

\section{Characteristics of the City's Parks}

\section{Park Facilities}

Descriptive statistics for all parks in the study are shown in Appendix 4. Of the 144 parks included in the study, $131(91.0 \%)$ had open/green spaces and $118(81.9 \%)$ had playgrounds, by far the most abundant features within all audited parks. Sixty parks had basketball courts (41.7\%), 48 had trails (33.3\%) and 34.0 had baseball fields (23.6\%); sports fields and tennis courts were found in about $15 \%$ of parks. Finally, less than $6 \%$ of all parks had swimming pools, splash pads, volleyball courts, fitness stations, skate parks, and off-leash dog parks; no parks had lakes/ponds.

\section{Park Amenities}

In terms of park amenities, around $95 \%$ of all parks had sidewalks adjacent to the park, sidewalks with curbs/ramps, and trash cans. Over $60 \%$ of parks had benches and picnic tables, while more than $80 \%$ had signs with animal rules. Approximately, $40 \%$ of all parks had public transit stops (e.g., bus stops/benches) and parking lots, $56.3 \%$ had dog waste bags, and about $25 \%$ of parks also had 
restrooms and picnic shelters (i.e., covered picnic tables). Over 12\% had traffic control mechanisms (e.g., crosswalks) and less than $3 \%$ of parks had external trails, grills, vending machines, baby changing stations, recycle containers, and emergency devices (e.g., phone, emergency directions).

\section{Park Aesthetic Features}

The most prevalent aesthetic feature across all parks was trees $(66 \%)$. About $20 \%$ of all parks had landscaping (e.g., flower beds, pruned bushes) and historical/educational features (e.g., monument, nature display, educational signs). Artistic features (e.g., statue, sculpture, or gazebo) were found at $13.2 \%$ of parks and only $2.8 \%$ had meadows (e.g., tall grassy area). No parks audited had wooded areas or water features (e.g., lake, pond).

\section{Park Quality Concerns}

For park quality concerns, more than $60 \%$ of parks had graffiti and about $20 \%$ of parks had threatening behavior (e.g., gangs, alcohol/drug use), roads through park, dangerous spots (e.g., pit/hole), and poor maintenance (e.g., overgrown grass/weeds/bushes or lack of grass). Less than $15 \%$ of park had vandalism, excessive litter (e.g., noticeable amounts of trash, broken glass), and excessive noise (e.g., noticeable sounds that are unpleasant or annoying). Excessive animal waste (e.g., noticeable amounts of dog waste) was almost never identified for all parks $(0.7 \%)$.

\section{Neighborhood Safety Concerns}

As with park quality concerns, graffiti was the most prevalent neighborhood safety concern (43.8\%); heavy traffic was second at 40.3\%. Inadequate lighting and poorly maintained properties (e.g., overgrown grass, broken windows) was recorded at just over $30 \%$ of the surrounding neighborhoods, while around $20 \%$ had excessive noise (e.g., noticeable sounds that are unpleasant or annoying), lack of eyes on street (e.g., absence of people, no houses or store fronts), and threatening behavior (e.g., gangs, drug/alcohol use). Less than 15\% surrounding neighborhoods had vandalism (e.g., damaged signs), 
excessive litter (e.g., noticeable amounts of trash, broken glass), or vacant/unfavorable buildings (e.g., abandoned houses, liquor stores).

\section{Descriptions of Park Measures}

Descriptions for park outcomes are included in Appendix 4. The median number of parks per census tract was $1.0(\mathrm{Q} 1=1, \mathrm{Q} 3=2)$, although census tracts ranged from having 0 to 9 parks per tract (skewness=2.30). Of the 112 total census tracts in the study, 72 tracts had at least one park, and 40 had no park at all. Park features include park facilities, amenities, and aesthetic features. The median number of facilities per park in each tract was $4.0(\mathrm{Q} 1=2.0, \mathrm{Q} 3=7.0)$, with a range from 0 to 14 facilities (e.g., play grounds, ball courts, fields, trails) (skewness=0.97). Park amenities had a median of $7.0(\mathrm{Q} 1=6.0$, $\mathrm{Q} 3=7.0)$ and a range of 1 to 15 amenities per park (skewness=0.43). A median number of $1.0(\mathrm{Q} 1=1.0$, $\mathrm{Q} 3=2.0)$ was found for park aesthetic features, with a range of 0 to 4 aesthetics features per park (skewness=0.89). Park quality concerns and neighborhood safety concerns were both categorized as park characteristics; the median number park quality concerns and neighborhood safety concerns was $1.5(\mathrm{Q} 1=0, \mathrm{Q} 3=2)$ and $2.0(\mathrm{Q} 1=1, \mathrm{Q} 3=4)$, respectively. Park quality concerns ranged from 0 to 7 (skewness=1.11), while neighborhood safety concerns ranged from 0.0 to 10.0 (skewness=1.03).

Based on univariate analysis (i.e., skewness and histograms), three park outcomes were skewed. Skewness was defined between a range of -1 and 1 , outcomes within that range were considered normally distributed, and those outside that range were not. The variables, park facilities, park amenities, and park aesthetic features were normally distributed. The skewed variables were park availability, park quality concerns, and neighborhood safety concerns. Histograms for the skewed variables further verified the non-parametric distribution of these variables. 


\section{Bivariate Analysis}

\section{Park Availability}

The first research question in the study looked at identifying park availability, more specifically, if there were differences in the number of parks by median household income and percent foreign-born tertiles. In order to test this, Appendix 5 shows the bivariate associations of park availability by median household income and percent foreign-born tertiles. Overall, the Kruskal-Wallis test indicated there was a statistically significant difference in the number of parks by the median house income tertiles $(\mathrm{p}=0.035)$. A post-hoc pairwise comparison (i.e., low versus medium, low versus high, and medium versus high), indicated that the medium income tertile had a significant difference in park availability, but only when compared with the high income tertile $(\mathrm{p}=0.011)$. The other pairwise comparisons were not statistically significant. A significant association between park availability and percent foreign-born tertiles was also not found $(\mathrm{p}=0.468)$.

\section{Park Features}

Park features include three separate variables: park facilities, park amenities, and park aesthetic features. The second research question inquired whether the number of park features (i.e., park facilities, amenities, and aesthetic features) differed across median household income and percent foreign-born tertiles. An ANOVA showed that park facilities $(\mathrm{p}<0.001)$ and park amenities $(\mathrm{p}=0.026)$ significantly differed across median household income tertiles, but park aesthetic features $(\mathrm{p}=0.746)$ did not; thus post-hoc tests were only conducted for park facilities and park amenities. Post-hoc pairwise comparisons indicate that there was a significant difference in the number of park facilities for medium income tertile compared to both the low $(\mathrm{p}=<0.001)$ and high income tertiles $(\mathrm{p}=0.015)$ (Appendix 5); park facilities did not significantly differ between the low and high tertiles $(\mathrm{p}=0.032)$. Pairwise comparisons between the three median household income tertiles and the number of amenities were also conducted; however significant differences were not found. 
Park facilities, park amenities, and park aesthetic features, all did not differ by percent foreignborn tertiles; the ANOVA p-values for park facilities, park amenities, and park aesthetics were 0.126, 0.197, and 0.912, respectively (Appendix 5).

\section{Park Characteristics}

The last research question was to identify whether there were differences in the number of park characteristics (i.e., park quality concerns and neighborhood safety concerns) by median household income and percent foreign-born tertiles. Park quality concerns and neighborhood safety concerns, significantly differed by median household income tertiles (Kruskal-Wallis p-values <0.001 (Appendix 5). Further, post-hoc pairwise comparisons indicate that the number of park quality concerns in the high income tertile was significantly different from the low $(\mathrm{p}<0.001)$ and medium $(\mathrm{p}<0.001)$ income tertiles. Pairwise comparisons also showed that there were significant differences in the number of neighborhood safety concerns between all three (low, medium, and high) income tertiles ( $\mathrm{p}<0.001$ for all three tests).

Significant differences in the number of park quality concerns and neighborhood safety concerns were found by percent foreign-born tertiles (Kruskal-Wallis p-values<0.001). Based on pairwise comparisons, all three foreign-born tertiles significantly differed in the number of park quality concerns, with p-values $<0.0167$. Pairwise comparisons also identified that the number of neighborhood safety concerns for the low foreign-born tertile significantly differed from the medium $(\mathrm{p}<0.001)$ and high $(\mathrm{p}<0.001)$ tertiles (Appendix 5). 


\section{Chapter 5: Discussion}

\section{Park AVAilability}

The first part of the study looked to identify any differences in the number of parks per median household income and percent foreign-born tertiles. In relation to park availability and median household income several, significant findings were found. Study results indicated that in the City of El Paso, park availability differed between income tertiles, but only between medium and high income tertiles. Furthermore, no significant differences were found comparing number of parks by foreign-born tertiles. These findings conflict with much of the literature that shows that the number of parks is higher in high income areas than lower income areas (Estabrooks et al., 2003; Gordon-Larsen et al., 2006; Moore et al., 2008). For example, Estabrooks et al. (2003) identified that low and medium socioeconomic areas had fewer free-for-use physical activity resources (i.e., parks) than neighborhoods of higher socioeconomic status, whereas in the present study only differences were found between the medium and high income tertiles. This may indicate that El Paso does not conform to the same park availability disparities that many other cities, not located on the U.S.-Mexico border, typically see. This non-conformity may be due to the fact the El Paso Parks and Recreations set out to create a park system based on Peter Harnik's, The Excellent Park System, and takes into account the community's needs and has kept to its promise (EPPRD, 2006).

While park availability in El Paso only differed between the medium and high income tertiles, this is noteworthy because other studies have not found differences in park availability across various socioeconomic statuses (Abercrombie et al., 2008; Timperio et al., 2008). Not finding differences in park availability and key sociodemographic factors (e.g., median household income and percentage of foreign-born) in the current study is also significant because much of the available literature states that racially/ethnically diverse and low acculturated areas have significantly lower access to parks and other 
recreational facilities (Moore et al., 2008; Weiss et al., 2011); this lack of differences in El Paso might be due to the city having such a high Hispanic (80.0\%) and foreign-born (25.7\%) population.

In neighborhoods of low socioeconomic status, high percentage of foreign-born and/or racial/ethnic make-up, the availability of public parks and other recreational facilities can be an important factor in promoting physical activity. This is because publically available recreational facilities are free, serve a large population, and act as sites where a large number of individuals can converge for physical activity and/or family gatherings. Overall, this study provides evidence that El Paso does not exactly follow the same park availability disparity trends as many other U.S. cites, thus further research should be conducted to see why these traits differ.

\section{Park Features}

The second part of the study sought to identify if the number of park features (i.e., park facilities, amenities, and aesthetic features) differed by median household income and percent foreign-born tertiles. Identifying these differences is important because park features (i.e., park facilities, amenities, and aesthetic features) have been shown to promote active lifestyles and positively influence health (Kaczynski et al., 2008; Potwarka et al., 2008). In the present study, the number of facilities and amenities, but not aesthetic features, was significantly different by income tertiles, and no significant differences were found in the number of park features (i.e., park facilities, amenities, and aesthetic features) across percent foreign-born tertiles. For park facilities, the medium income tertile was significantly different from low and high; there were no significant differences between low and high income tertiles.

The finding of no differences in the number of park facilities between low and high income groups conflicts with the U.S.-wide ImpacTeen Project that indicated that higher median income households had higher availability of physical activity settings (e.g., parks, sports areas, and green spaces) than lower income and high minority areas (Powell et al., 2004). The fact that no differences 
were found between the low and high income tertiles once again suggests that El Paso does not demonstrate the park disparity issues that other cities typically face, at least in terms of facilities. El Paso's uniqueness can also be seen in that no differences were found in amenities or aesthetic features across income and foreign-born tertiles. These findings conflict with much of the literature as was shown in one study where fewer facilities and amenities were found in areas of lower socioeconomic status (Crawford et al., 2008). Moreover, while few studies have looked at the distribution of park features and foreign-born populations, one study found that the number of park facilities (and total number of parks) was significantly lower when looking at areas of high percent foreign-born individuals (Weiss et al., 2011). One item to mention is that while the overall number of park features (i.e., park facilities, amenities, and aesthetic features) did not differ across foreign-born tertiles, certain areas of El Paso may have higher abundance of one and lack other important features, which may not accurately provide equal distribution of park features. Additionally, the quality of these features may have also differed between the income and foreign-born tertiles.

The presence of park features (park facilities, amenities, and aesthetic features) has been shown to promote physical activity (Floyd et al., 2008; Kaczynski et al., 2008; Potwarka et al., 2008). This is important to know because El Paso seems to have equal distribution of park resources. Furthermore, having these features in place can help tackle physical inactivity and obesity issues in the region, although further investigations need to be conducted. Overall, it can be said again that El Paso differs from the many other cities in terms of park features inequalities.

\section{Park Characteristics}

The third and final part of the study looked to identify differences in park characteristics (i.e., park quality concerns and neighborhood safety concerns) by median household income and percent foreign-born tertiles. In the City of El Paso, there were significant differences in the number of park quality concerns and neighborhood safety concerns by income and foreign-born tertiles. In the present 
study, the high income tertile was significantly different in the number of park quality concerns versus the low and medium income groups. The number of neighborhood safety concerns by all income tertiles was significantly different, as well as park quality concerns and the three foreign-born tertiles. The number of neighborhood safety concerns with the low foreign-born tertile was significantly different from the medium and high tertiles. While the issues of park availability and park features did not completely imitate past research, it looks like park characteristics seems to be the one area where El Paso does match the few studies that examine park quality and safety concerns in low-socioeconomic and demographically diverse populations. For example, the findings of the present study agree with a previous study conducted in Edmonton, Canada (Smoyer-Tomic et al., 2004), although in the present study percent foreign-born was assessed rather than percent minority. In this study, the authors found that low socioeconomic and high minority neighborhoods had equal access to parks but that those parks were of lesser quality. A study in Chicago, IL, also described that lower-income racial/ethnic minority neighborhoods had lower quality recreational areas (Gobster, 1998); in El Paso, differences were found between low and high income and foreign-born tertiles. The present study also agrees with another study (Coen et al., 2006) conducted in Montreal, Canada that examined quality of neighborhood parks, although in Coen et al's study socioeconomic status or demographic composition of the neighborhood were not assessed. In that study, the authors found that parks located in poor health areas displayed several pronounced material disadvantages, concentration of physical incivilities, limited provision of facilities for physical exercise, and adjacency to industrial sites and multi-lane roads. Moreover, the existence of differences in park characteristics (i.e., park quality concerns and neighborhood safety concerns) between income and foreign-born tertiles is discouraging because lack of quality and safety may decrease park usage, as was shown in the literature (Babey et al., 2008; Ries, Yan, \& Voorhees, 2011; Veugelers, Sithole, Zhang, \& Muhajarine, 2008). Furthermore, understanding these effects is important because park quality has been shown to be a strong predictor of park use and physical activity (Coen et 
al., 2006; Perry et al., 2011). Improving the quality of park resources could be an important strategy to increase physical activity and eliminate health disparities, especially in low socioeconomic and highly demographically diverse neighborhoods (Moore et al., 2008).

\section{SignifiCANCE OF STUdY}

The study contributes to the understanding of disparities in physical activity environments among border communities. It is important to understand that border regions (i.e., counties) are among the poorest in the country (City of El Paso Department of Public Health, 2008), possibly making it more difficult to equally disperse recreational facilities. The CPAT has been shown to have a high inter-rater reliability for a majority of the items on the tool, aiding itself to stakeholders, specifically community members, as a tool that they can use easily and confidently (Kaczynski et al., 2012). The study hopes that community members will use the CPAT to increase their awareness of the park issues El Paso faces. Increased awareness of park disparities can help citizens advocate for higher quality and more resourceful parks. Thoroughly assessing physical activity environments in the region can assist policy makers, with the help of other stakeholders, in identifying better strategies for park development and facilitate processes to make El Paso parks more usable, safe, and accessible for physical activity. Community stakeholders such as policy makers, city planners, and tax payers can also use the CPAT as a means to justify allocation of funds and/or improvements to parks and recreational facilities. Finally, the study can further prove that park availability, features, and characteristics in border communities may not reflect park availability, features, and characteristics in other regions; especially, in areas where low-income and demographically diverse individuals are less prone to live. As for this study, El Paso is quite unique in that the findings show that the city does not conform to the same disparities that exist in non-border regions. 


\section{IMPLICATIONS FOR FUTURE RESEARCH}

Future research should look for any discrepancies in allocation of funds within El Paso park districts and identify if parks in low income and high demographically diverse neighborhoods are of less, better, or equal quality than neighborhoods of higher income and less demographically diverse populations. Future research can also assess past and present policies that support further development of land for park use and equal distribution of those resources. The present study only looked at differences in the total number of park features by income and foreign-born tertiles; therefore, more research should be conducted to look at individual facilities, amenities, and aesthetic features, and their comparative quality. The CPAT objectively measures the quality and safety concerns of the park and surrounding neighborhood, although an auditor's perception of quality and safety may not actually reflect the opinions of the individuals who use the park or live in the surrounding neighborhood; thus further research should be conducted to better assess perceptions of safety within the park and surrounding neighborhood, possible using a combination of audit tools and health behavior models (e.g., health belief model, theory of reasoned action). Examining each feature (e.g., facilities, amenities, and aesthetic features) individually would also aid in identifying if certain areas had more than one type of feature than another, and if so, whether that unequal distribution of features drives further disparities in availability of park features and healthy lifestyle across different socioeconomic and demographically diverse areas. Finally, future research should also look at the relationship between the number and type of park features (e.g., park facilities, amenities, and aesthetic features) and park-based physical activity; as this will help identifying which specific features encourage/discourage individuals to the visit a park.

\section{LIMITATIONS}

There were several limitations in the present study. First, the utilization of a cross-sectional study design posed limitations related to the ability to infer and show causality, this is because cross-sectional studies only look at one point in time, and do not assess temporality. The use of a cross-sectional study also introduces the limitation of seasonal and time-of-day variability because conducting park 
assessments during certain seasons or hours may change how the park is audited; for example, if a park is audited during the night hours, the auditor may be more likely to perceive threatening behavior than during the day hours. Additionally, the use of aggregate (i.e., population-based) data rather than individual data, limits inferences that can be made at an individual level. The lack of information on park utilization further limits the ability to link physical activity to park availability, features, or the characteristics they may contain. Conducting the study in a largely Hispanic border city may limit the generalizability of the results of the study to this particular population and region.

The study only examined the relationship between park availability, features, and characteristics by medium household income and percent foreign-born variables. This poses a limitation because other influences (e.g., environmental factors and individual behavior) are overlooked. The use of census tracts also introduces issues associated with Modifiable Areal Unit Problems (MAUP), where any influences the study identified between park variables and ACS variables can be limited (i.e., biased) because of the scale and boundary effects of census tracts. More specifically, this limitation addresses that people may utilize parks outside of their census tract, which signifies that park availability within each tract may not accurately reflect true availability of parks and their features. While the use of census tracts as a unit of analysis may pose a limitation, several other studies have previously used the census tract method to examine large areas (Abercrombie et al., 2008; Estabrooks et al., 2003; Moore et al., 2008; Vaughan, 2011); and is the reason why census tracts were used in the current study.

Another limitation in the current study was that only pocket, neighborhood, and community parks listed by El Paso Parks and Recreation Department were audited. While these parks comprise the majority of El Paso's publically available parks (over 90\%), other studies could benefit from assessing all parks (e.g. linear, special use, open-land, state, and national parks) within the area (e.g., local, state, and national) because these sites can be utilized for physical activity. This study also did not look at 
private-use, schools playgrounds, or parks overseen by state and/or national jurisdiction although these sites are typically require payment to enter the premises, which limit useability of the those places.

Finally, while the study used a comprehensive and reliable audit tool (i.e., the CPAT) that looks at a wide-range of park features (e.g., facilities, amenities, and aesthetics features) and park characteristics (e.g., park quality concerns and neighborhood safety concerns), only the number (i.e., sum) of each item, and the presence of differences between income and foreign-born tertiles was analyzed. The individual useability and quality of each feature was not taken into account in the study, although the CPAT does captures these descriptions. Future studies should look into these CPAT variables for analysis.

\section{STRENGTHS}

Despite its limitations, this study had several strengths. A major strength of the study was the study setting of the City of El Paso. The city is a unique study setting because it is located on the U.S. Mexico Border, and has a majority Hispanic population. Few studies have examined differences in park availability, features, and characteristics by income and foreign-born populations within a border community. This is important because understanding these relationships may impact physical activity and contribute in decreasing obesity-related health issues among Hispanics and other border communities.

Another strength of the study was that all parts of the CPAT were used. This incorporated information about park facilities, amenities, aesthetic features, park quality concerns, and neighborhood safety concerns; this covers a broad range of factors that play an important role in park usage for physical activity. The fact that in-person park audits were conducted for each park within the City of El Paso was also a major strength because this allowed for in-depth and complete assessing of park features and characteristics, and helped exclude parks that were not truly available for use. Finally, because all 
park audits were conducted during daylight hours, increased visibility of park features and characteristics may have allowed for better assessments, rather than night-time audits.

\section{CONCLUSION}

This study aimed to identify differences in park availability, park features (i.e., park facilities, amenities, and aesthetic features), and park characteristics (i.e., quality/safety concerns of the park and surrounding neighborhood) by medium household income and percent foreign-born tertiles within a U.S.-Mexico border community. While some differences were not found, there were significant differences in the majority of park features and characteristics by income and foreign-born categories. This study further demonstrates that publically available recreational facilities, and their features and characteristics, are not equally distributed and that further research must be conducted to close this gap and eliminate disparities therein. In conclusion, this study adds to the current literature that is available on physical activity environments and seeks to add to the value that parks and recreational facilities play in promoting physical activity and healthy lifestyles, specifically within U.S.-Mexico Border communities. 


\section{References}

Addy, C. L., Wilson, D. K., Kirtland, K. A., Ainsworth, B. E., Sharpe, P., \& Kimsey, D. (2004). Associations of perceived social and physical environmental supports with physical activity and walking behavior. American Journal of Public Health, 94(3), 440-443.

Aileen, M., Kelly, E., Amy, H., Sara, H., \& Daniel, R. (2007). Exploring associations between physical activity and perceived and objective measures of the built environment. Journal of Urban Health, 84(2), 162-184.

American Community Survey (2010). Race and Hispanic origin of the foreign-born population in the United States: 2007. American Community Survey Reports. Retrieved from: http://www.census.gov/prod/2010pubs/acs-11.pdf.

American Community Survey (2011a). About the American Community Survey. Retrieved from: http://www.census.gov/acs/www/about_the_survey/american_community_survey/.

American Community Survey (2011b). When to use 1-year, 3-year, or 5-year estimates. Retrieved from: http://www.census.gov/acs/www/guidance_for_data_users/estimates/.

Anchondo, T., \& Ford, P. (2011). Neighborhood deprivation, neighborhood acculturation, and the retail food environment in a U.S.-Mexico border urban area. In press.

Atkinson, J. L., Sallis, J. F., Saelens, B. E., Cain, K. L., \& Black, J. B. (2005). The association of neighborhood design and recreational environments with physical activity. American Journal of Health Promotion, 19(4), 304-309.

Ball, K., Bauman, A., Leslie, E., \& Owen, N. (2001). Perceived environmental aesthetics and convenience and company are associated with walking for exercise among Australian adults. Preventive Medicine, 33(5), 434-440.

Bauman, A. E., \& Bull, F. C. (2007). Environmental correlates of physical activity and walking in adults and children: A review of reviews. National Institute of Health and Clinical Excellence. Retrieved from: http://www.nice.org.uk/guidance/index.jsp?action=download\&o=34740.

Blahna, D., \& Black, K. S. (1992). Racism: a concern for recreation resource managers? In managing urban and high-use recreation settings. Leisure Sciences, 24,143-159.

Blanchard, C. M., McGannon, K. R., Spence, J. C., Rhodes, R. E., Nehl, E., \& Baker, F. et al. (2005). Social ecological correlates of physical activity in normal weight, overweight, and obese individuals. International Journal of Obesity, 29(6), 720-726.

Bedimo-Rung, A.L., Mowen, A.J., \& Cohen, D.A. (2005). The significance of parks to physical activity and public health: A conceptual model. American Journal of Preventive Medicine, 28(2S2), 159-168.

Boone-Heinonen, J., Casanova, K., Richardson, A. S., \& Gordon-Larsen, P. (2010). Where can they 
play? Outdoor spaces and physical activity among adolescents in U.S. urbanized areas.

Preventive Medicine, 51(3/4), 295-298. doi:10.1016/j.ypmed.2010.07.013

Bocarro, J. N., Casper, J., Henderson, K. A., Floyd, M. F., Moore, R., Kanters, M. A., \& Edwards, M. B. (2009). Physical activity promotion in North Carolina: Perceptions of public park and recreation directors. Journal of Park \& Recreation Administration, 27(1), 1-16.

Brownson, R. C., Baker, E. A., Housemann, R. A., Brennan, L. K., \& Bacak, S. J. (2001). Environmental and policy determinants of physical activity in the United States. American Journal of Public Health, 91(12), 1995-2003.

Burris, S. (2011). From health care law to the social determinants of health: A public health law research perspective. University of Pennsylvania Law Review, 159(6), 1649-1667.

Carson, V., Kuhle, S., Spence, J. C., \& Veugelers, P. J. (2010). Parents' perception of neighborhood environment as a determinant of screen time, physical activity and active transport. Canadian Journal of Public Health, 101(2), 124-127.

Centers for Disease Control and Prevention. (2001). Physical activity trends: 1990-1998. Morbidity and Mortality Weekly Report; 50, 166-169.

Centers for Disease Control and Prevention (2008). Youth risk behavior surveillance-United States, 2007; Morbidity and Mortality Weekly Report.

Centers for Disease Control and Prevention. (2009a) Differences in prevalence of obesity among Black, White, and Hispanic adults - United States, 2006-2008. Morbidity and Mortality Weekly Report, 58(27), 740-744.

Centers for Disease Control and Prevention. (2009b). Overweight and obesity. US Department of Health and Human Service on-line government document. Retrieved from: http://www.cdc.gov/obesity/causes/health.html

Centers for Disease Control and Prevention. (2011). Physical activity for everyone; physical activity and health. US Department of Health and Human Service on-line government document. Retrieved from: http://www.cdc.gov/physicalactivity/everyone/health/index.html.

Chad, K. E., Reeder, B. A., Harrison, E. L., Ashworth, N. L., Sheppard, S. M., \& Schultz, S. L. et al. (2005). Profile of physical activity levels in community-dwelling older adults. Medicine and Science in Sports and Exercise, 37(10), 1774-1784.

City of El Paso. (2004). Population and housing by planning area \& census tract. Retrieved from: http://www.elpasotexas.gov/demographics.asp.

City of El Paso Department of Public Health. (2008). How healthy are we? Selected measures for El Paso, Texas 2008. Retrieved from:

http://www.elpasotexas.gov/health/_documents/measures2008/complete\%20Document_group_input final.pdf\#view=fitH 
Coen, S. E., \& Ross, N. A. (2006). Exploring the material basis for health: Characteristics of parks in Montreal neighborhoods with contrasting health outcomes. Health \& Place, 12, 361-371.

Cohen, D. A., Ashwood, J. S., Scott, M. M., Overton, A., Evenson, K. R., Staten, L. K., et al. (2006). Public parks and physical activity among adolescent girls. Pediatrics, 118, 1381-1389.

Cohen D. A., McKenzie, T. L., Sehgal, A., Williamnson, S., Golinelli, D., \& Lurie, N. (2007). Contribution of public parks to physical activity. American Journal of Public Health, 97(3), 509-514.

Giles-Corti, B., Donovan, R., \& Holman, C. (1996). Factors influencing the use of physical activity facilities: results from qualitative research. Health Promotion Journal of Australia, 6, 16-21.

Coen, S. E., \& Ross, N. A. (2006). Exploring the material basis for health: Characteristics of parks in Montreal neighborhoods with contrasting health outcomes. Health \& Place, 12, 361-371.

Crawford, D., Timperio, A., Giles-Corti, B., Ball, K., Hume, C., Roberts, R., \& Andrianopoulos, N., et al. (2008). Do features of public open spaces vary according to neighborhood socio-economic status? Health \& Place, 14, 889-893.

Cutts, B. B., Darby, K. J., Boone, C. G., \& Brewis, A. (2009). City structure, obesity, and environmental justice: An integrated analysis of physical and social barriers to walkable streets and park access. Social Science \& Medicine, 69, 1314-1322.

Day, R. (2008). Local environments and older people's health: dimensions from a comparative qualitative study in Scotland. Health and Place, 14, 299-312.

De Bourdeaudhuij, I., Sallis, J. F., \& Saelens, B. E. (2003). Environmental correlates of physical activity in a sample of Belgian adults. American Journal of Health Promotion, 18(1), 83-92.

Deshpande, A. D., Baker, E. A., Lovegreen, S. L., \& Brownson, R. C. (2005). Environmental correlates of physical activity among individuals with diabetes in the rural Midwest. Diabetes Care, 28(5), 1012-1018.

Diez Roux, AV, \& Mair, C. (2010). Neighborhoods and health. Annuals of New York Academy of Sciences, 1186, 125-145.

El Paso Parks and Recreation Department. (2006). The parks and recreation master plan. City of El Paso, Texas. Retrieved from: http://www.elpasotexas.gov/parks/master.asp.

Estabrooks, P. A., Lee, R. E., \& Gyurcsik, N. C. (2003). Resources for physical activity participation: Does availability and accessibility differ by neighborhood socioeconomic status? Annals of Behavioral Medicine: A Publication of the Society of Behavioral Medicine, 25(2), 100-104.

Finkelstein, E., Trogdon, J., Cohen, J., \& Dietz, W. (2009). Annual medical spending attributable to obesity: Payer- and service-specific estimates. Health Affairs, 28(5), w822-w831. 
Flegal, K. M., Carroll, M. D., Ogden, C. L., \& Curtin, L. R. (2010). Prevalence and trends in obesity smong US sdults, 1999-2008. Journal of the American Medical Association, 303(3), 235-241.

Floyd, M. F., Spengler, J. O., Maddock, J. E., Gobster, P. H., \& Suau, L. J. (2008). Park-based physical activity in diverse communities of two United States cities. American Journal of Preventive Medicine, 34, 299-305.

Friel, S., Akerman, M., Hancock, T., Kumaresan, J., Marmot, M., Melin, T., \& Vlahov, D. (2011). Addressing the social and environmental determinants of urban health equity: Evidence for action and a research agenda. Journal of Urban Health, 88(5), 860-874.

Frank, L. D., \& Engelke, P. (2005). Multiple impacts of the built environment on public health: walkable places and the exposure to air pollution. International Regional Science Review, 28(2), 193-216.

Ford, P.B., \& Dzewaltowski, D. A. (2008). Disparities in obesity prevalence due tovariation in the retail food environment: Three testable hypotheses. Nutrition Reviews, 66, 216-28.

Giles-Corti, B., \& Donovan, R. J. (2002). Socioeconomic status differences in recreational physical activity levels and real and perceived access to a supportive physical environment. Preventive Medicine, 35, 601-611.

Giles-Corti, B., Broomhall, M. H., Knuiman, M., Collins, C., Douglas, K., \& Ng, K. et al. (2005). Increasing walking: How important is distance to, attractiveness, and size of public open space? American Journal of Preventive Medicine, 28(2S2), 169-176.

Giles-Corti, B., Kelty, S. F., Zubrick, S. R., \& Villanueva, K. P. (2009). Encouraging Walking for Transport and Physical Activity in Children and Adolescents How Important is the Built Environment? Sports Medicine, 39(12), 995-1009.

Gobster, P. H. (1998). Urban parks as green walls or green magnets? Interracial relations in neighborhood boundary parks. Landscape and Urban Planning, 41, 43-55.

Godbey, G. C., Caldwell, L. L., Floyd, M., \& Payne, L. L. (2005). Contributions of leisure studies and recreation and park management research to the active living agenda. American Journal of Preventive Medicine, 28, 150-158.

Gomez, J. E., Johnson, B. A., Selva, M., \& Sallis, J. F. (2004). Violent crime and outdoor physical activity among inner-city youth. Preventive Medicine, 39(5), 876-881.

Gordon-Larsen, P., Nelson, M. C., Page, P., \& Popkin, B. M. (2006). Inequality in the built environment underlies key health disparities in physical activity and obesity. Pediatrics, 117(2), 417-424.

Halfon, N., Larson, K., \& Russ, S. (2010). Why social determinants? Healthcare Quarterly, 14, 9-20.

Handy, S., Xinyu, C., \& Mokhtarian, P. (2006). Self-Selection in the relationship between the built environment and walking. Journal of the American Planning Association, 72(1), 55-74. 
Henderson, K. A. (2007). Urban parks and trails and physical activity. Annals of Leisure Research, 9(4), 201-213.

Humpel, N., Owen, N., \& Leslie, E. (2002). Environmental factors associated with adults' participation in physical activity: a review. American Journal of Preventive Medicine, 22(3), 188-199.

Joassart-Marcelli, P. (2010). Leveling the playing field? Urban disparities in funding for local parks and recreation in the Los Angeles region. Environment and Planning, 45(5), 1174-1192.

Kaczynski, A. T. \& Henderson, K. A. (2007). Environmental correlates of physical activity: A review of evidence about parks and recreation. Leisure Sciences, 29(4), 315-354.

Kaczynski, A.T., Potwarka, L. R., \& Saelens, B. E. (2008). Association of park size, distance, and features with physical activity in neighborhood parks. American Journal of Public Health, 98(8), 1451-1456.

Kaczynski, A. T., \& Havitz, M. E. (2009). Examining the relationship between proximal park features and residents' physical activity in neighborhood parks. Journal of Park \& Recreation Administration, 27(3), 42-58.

Kaczynski, A.T., Wilhelm Stanis, S., \& Besenyi, G. (2012). Development and testing of a community stakeholder park audit tool. American Journal of Preventive Medicine, 42(3), 242-24).

Kawachi, I., \& Kennedy, B. (1997). Socioeconomic determinants of health : Health and social cohesion: why care about income inequality? British Medical Journal, 314, 1037.

Krieger, N., Zierler, S., Hogan, J., Waterman, P., Chen, J., Lemieux, K., et al. (2003). Geocoding and measurements of neighborhood socioeconomic position: A U.S. perspective. Neighborhoods and Health (pp. 147).

Kumanyika, S., \& Grier, S. (2006). Targeting interventions for ethnic minority and low-income populations. Future of Children, 16(1), 187-207.

Kurland, K., \& Gorr Wilpen. (2006). GIS tutorial for health. Redlands, California: ESRI Press.

Lee, R.E., Booth, K.M., Reese-Smith, J.Y., Regan, G., \& Howard, H.H. (2005). The Physical Activity Resource Assessment (PARA) instrument: Evaluating features, amenities, and incivilities of physical activity resources in urban neighborhoods. International Journal of Behavioral Nutrition and Physical Activity, 2, 13-21.

Leslie, E., Cerin, E., \& Kremer, P. (2010). Perceived neighborhood environment and park use as mediators of the effect of area socio-economic status on walking behaviors. Journal of Physical Activity and Health, 7(6), 802-810.

Lovasi, G., Moudon, A., \& Pearson, A., et al. (2008). Using built environment characteristics to predict walking for exercise. International Journal of Health Geographics, 7, 1-13. 
Lovasi, G., Neckerman, K., Quinn, J., Weiss, C., \& Rundle, A. (2009). Individual or neighborhood disadvantage modifies the association between neighborhood walkability and body mass index. American Journal of Public Health, 99(2), 264-285.

Lovasi, G., Jacobson, J., Quinn, J., Neckerman, K., Ashby-Thompson, M., \& Rundle, A. (2011). Is the environment near home and school associated with physical activity and adiposity of urban preschool children? Journal Of Urban Health, 88(6), 1143-1157.

Moody, J. S., Prochaska, J. J., Sallis, J. F., McKenzie, T. L., Brown, M, \& Conway, T. L. (2004). Viability of parks and recreation centers as sites for youth physical activity promotion. Health Promotion Practice, 5(4), 438-443.

Moore, L. V., Diez-Roux, A. V., Evenson, K. R., McGinn, A. P., \& Brines, S. J. (2008). Availability of recreational resources in minority and low socioeconomic status areas. American Journal of Preventive Medicine, 34(1), 16-22.

Mota, J., Almeida, M., Snatos, P., \& Ribeiro, J. (2005). Perceived neighborhood environments and physical activity in adolescents. Preventive Medicine, 41(5-6), 834-836.

Ogden, C. L., Carroll, M. D., Curtin, L. R., Lamb, M. M., \& Flegal, K. M. (2010). Prevalence of high body mass index in US children and adolescents, 2007-2008. Journal of the American Medical Association, 303(3), 242-249.

Parks, S. E., Housemann, R. A., \& Brownson, R. C. (2003). Differential correlates of physical activity in urban and rural adults of various socioeconomic backgrounds in the United States. Journal of Epidemiology and Community Health, 57(1), 29-35.

Perry, C., Saelens B., \& Thompson, B. (2010). Rural Latino youth park use: Characteristics, park amenities, and physical activity. Journal of Community Health, DOI 10.1007/s10900-010-9320z.

Potwarka, L. R., Kaczynski, A. T., \& Flack, A. L. (2008). Places to play: Association of park space and facilities with healthy weight status among children. Journal of Community Health, 33(5), 344350.

Powell, L., Slater, S., \& Chaloupka, F. J. (2004). The relationship between community physical activity settings and race, ethnicity and socioeconomic status. Evidence-Based Preventive Medicine, 1(2), 135-44.

Powell, L. M., Slater, S., Chaloupka, F. J., \& Harper, D. (2006). Availability of physical activity-related facilities and neighborhood demographic and socioeconomic characteristics: A national study. American Journal of Public Health, 96(9), 1676-1680.

Richardson, L. D., \& Norris, M. (2010). Access to health and health Care: How race and ethnicity Matter. Mount Sinai Journal Of Medicine, 77(2), 166-177.

Ries, A. V., Gittelsohn, J., Voorhees, C. C., Roche, K. M., Clifton, K. J., \& Astone, N. M. (2008). The environment and urban adolescents' use of recreational facilities for physical activity: A qualitative study. American Journal of Health Promotion, 23(1), 43-50. 
Ries, A. V., Yan, A. F., \& Voorhees, C. C. (2011). The Neighborhood Recreational Environment and Physical Activity Among Urban Youth: An Examination of Public and Private Recreational Facilities. Journal Of Community Health, 36(4), 640-649.

Rodríguez, D. A., Cho, G., Evenson, K. R., Conway, T. L., Cohen, D., Ghosh-Dastidar, B., \& ... Lytle, L. A. (2012). Out and about: Association of the built environment with physical activity behaviors of adolescent females. Health \& Place, 18(1), 55-62.

Robert, S. A., \& Booske, B. C. (2011). US opinions on health determinants and social policy as health policy. American Journal of Public Health, 101(9), 1655-1663.

Roemmich, J. N., Epstein, L. H., Raja, S., Yin, L., Robinson, J., \& Winiewicz, D. (2006). Association of access to parks and recreational facilities with the physical activity of young children. Preventive Medicine, 43, 437-441.

Roemmich, J. N., Epstein, L. H., Raja, S., \& Yin, L. (2007). The neighborhood and home environments: Disparate relationships with physical activity and sedentary behaviors in youth. Annals of Behavioral Medicine, 33(1), 29-38.

Saelens, B.E., Sallis, J.F., \& Frank, L.D. (2003). Environmental correlates of walking and cycling: Findings from the transportation, urban design, and planning literatures. Annals of Behavioral Medicine, 25(2), 80-91.

Saelens, B. E. \& Handy, S. (2008). Built environment correlates of walking: A review. Medicine Science in Sports and Exercise, 40, 550-566.

Sallis, J., Cervero, R., Ascher, W., Henderson, K., Kraft, M., \& Kerr, J. (2006). An ecological approach to creating active living communities. Annual Review of Public Health, 27(1), 297-322.

Sallis, J., \& Glanz, K. (2009). Physical activity and food environments: Solutions to the obesity epidemic. Milbank Quarterly, 87(1),123-154.

Samimi, A., \& Mohammadian, A. (2010). Health Impacts of Urban Development and Transportation Systems. Journal of Urban Planning \& Development, 136(3), 208- 213.

Smoyer-Tomic, K. E., Hewko, J. N., \& Hodgson, M. J. (2004). Spatial accessibility and equity of playgrounds in Edmonton, Canada. The Canadian Geographer, 48(3), 287-302.

Song, R., Hall, H., Harrison, K., Sharpe, T., Lin, L. S., \& Dean, H. D. (2011). Identifying the impact of social determinants of health on disease rates using correlation analysis of area-based summary information. Public Health Reports, 12670-80.

Tannerfeldt, G., \& Ljung, P. (2006). More urban less poor: An introduction to urban development and management. London, UK: Sida/Earthscan Publications. 
Tiwari, R., Pandey, M., \& Sharma, A. (2010). An Approach to Human Adaptability towards its Built Environment: A Review. Energy \& Power Engineering, 2(2), 90-94.

Timperio, A., Crawford, D., Telford, A., \& Salmon, J. (2004). Perceptions about the local neighborhood and walking and cycling among children. Preventive Medicine, 38, 39-47.

Timperio, A., Ball, K., Salmon, J., Roberts, R., \& Crawford, D. (2007). Is availability of public open space equitable across areas? Health \& Place, 13(2), 335-340.

Timperio, A., Giles-Corti, B., Crawford, D., Andrianopoulos, N., Ball, K., Salmon, J., \& Hume, C. (2008). Features of public open spaces and physical activity among children: Findings from the CLAN study. Preventive Medicine, 47, 514-518.

Troiano, R. P., Berrigan, D., Dodd, K. W., Masse, L. C., Tilert, T., \& McDowell, M. (2008). Physical Activity in the United States Measured by Accelerometer. Medicine \& Science in Sports \& Exercise, 40(1), 181-188.

United States Census Bureau (2000). State \& County QuickFacts: El Paso, Texas. Washington, DC: US Bureau of the Census. Retrieved from: http://quickfacts.census.gov/qfd/states/48/4824000.html.

United States Census Bureau. (2001a). Cartographic Boundary Files. Washington, DC: US Bureau of the Census. Retrieved from: http://www.census.gov/geo/www/cob/tr_metadata.html.

United States Census Bureau. (2001b). Profile of General Demographic Characteristics: 2000 City of El Paso, Texas. Washington, DC: US Bureau of the Census.

United States Census Bureau. (2008). Annual Estimates of the Resident Population for Incorporated Places Over 100,000, Ranked by July 1, 2008 Population: April 1, 2000 to July 1, 2008.

Washington, DC: US Bureau of the Census.

United States Census Bureau. (2011a). Income: Measures of income in the U.S. Census. Washington, DC: US Bureau of the Census. Retrieved at: http://www.census.gov/hhes/www/income/income.html.

United States Census Bureau. (2011b). Population estimates terms and definitions. Washington, DC: US Bureau of the Census. Retrieved at: http://www.census.gov/popest/about/terms.html.

United States Census Bureau. (2011c). Dynamics of Economic Well-Being: Fluctuations in the U.S. Income Distribution, 2004-2007. Washington, DC: US Bureau of the Census. Retrieved at: http://www.census.gov/prod/2011pubs/p70-124.pdf.

United States Department of Health and Human Services. (1996). Physical activity and health: A report of the surgeon general. Washington, D.C.: U.S. Government Printing Office.

United States Department of Health and Human Services. (2008). Physical Activity Guidelines for Americans. Retrieved from: www.health.gov/paguidelines. 
United States Department of Health and Human Services. (2010). Healthy People 2020: Physical Activity Objectives. US Government Printing Office. Retrieved from:

http://www.healthypeople.gov/2020/topicsobjectives2020/default.aspx.

Vaughn, K.B. (2011). Environmental justice and physical activity: Examining disparities in access to parks in Kansas City, Missouri. (Unpublished thesis). Kansas State University, Manhattan, Kansas.

Veugelers, P., Sithole, F., Zhang, S., \& Muhajarine, N. (2008). Neighborhood characteristics in relation to diet, physical activity and overweight of Canadian children. International Journal of Pediatric Obesity, 3(3), 152-159.

Viswanath, K., \& Ackerson, L. K. (2011). Race, ehnicity, language, social class, and health communication inequalities: A nationally-representative cross-sectional study. Plos ONE, 6(1), $1-8$.

Weiss, C. C., Purciel, M., Bader, M., Quinn, J. W., Lovasi, G., Neckerman, K. M., \& Rundle, A. G. (2011). Reconsidering access: Park facilities and neighborhood disamenities in New York City. Journal of Urban Health, 88(2), 297-310.

Wilcox, S., Castro, C., King, A. C., Houseman, R. A., \& Brownson, R. C. (2000). Determinants of leisure time physical activity in rural compared with urban older and ethnically diverse women in the United States. Journal of Epidemiology and Community Health, 54, 667-672.

Wilhelm Stanis, S. A., Schneider, I. E., Shinew, K. J., Chavez, D. J., \& Vogel, M. C. (2009). Physical activity and the recreation opportunity spectrum: Differences in important site attributes and perceived constraints. Journal of Park and Recreation Administration, 27(4), 73-91.

Wilson, D. K., Kirtland, K. A., Ainsworth, B. E., \& Addy, C. L. (2004). Socioeconomic status and perceptions of access and safety for physical activity. Annals Of Behavioral Medicine, 28(1), 2028.

Wolch, J., Jerrett, M., Reynolds, K., McConnell, R., Chang, R., Dahmann, N., \& Brady, K., et al. (2011). Childhood obesity and proximity to urban parks and recreational resources: A longitudinal cohort study. Health \& Place, 17(1), 207-214.

World Health Organization. (2008). "Key Concepts." Final Report of the Commission on Social Determinants of Health. Geneva, Switzerland: World Health Organization Commission on Social Determinants of Health. Retrieved from: http://www.who.int/social_determinants/thecommission/finalreport/key_concepts/en/index.html. 


\section{Appendix}

\section{Appendix Contents}

1. Community Park Audit Tool (CPAT)

2. TABLE 1: Descriptions and Examples of Pocket, Neighborhood, and Community Parks

3. TABLE 2: Number of Parks by Park Type and Region

4. TABLE 3: Descriptive Analysis of Social Determinants of Health and Park Measures

5. TABLE 4: Bivariate Association of Park Availability, Features, and Characteristics by Median Household Income and Percent Foreign-born Tertiles 


\section{COMMUNITY PARK AUDIT TOOL}

\section{Instructions}

Before you begin, review the brief training guide and audit tool and try to locate a map of the park. This is important to ensure each question and response option is clear when you are making your ratings. Then, go to the park and proceed with filling out this audit tool. The tool ( 6 pages) is divided into four sections that focus on different aspects of the park environment. Additional instructions are provided within each section.

Tips for Using the Community Park Audit Tool (CPAT)

- Drive, bike, or walk around the park to get a feel for the contents and characteristics of the park and surrounding neighborhood.

- The CPAT is organized such that questions on similar topics are grouped into logical sections and the four sections are arranged in the order that you might encounter them during your audit. However, you may need to switch between sections or pages as you complete the park audit. Therefore, it is important to review and be familiar with all of the tool sections and questions before you begin your audit.

- It is also important that you check back through the full document (6 pages) when you are finished to ensure you have completed all the sections and questions.

- Space is provided at the end of each section (and some individual questions) where you can take notes or record comments as you complete your audit. The margins or back of each page (if copied singlesided) can also be used to take notes, but please be sure that all relevant information is transferred to appropriate places on the tool and that all questions are fully answered using the format provided.

- If you see anything during your audit that requires immediate attention, contact the local parks department.

\section{Section 1: Park Information}

Park Name:

Observer Name or ID:

Park Address/Location:

Were you able to locate a map for this park? $\square$ No $\square$ Yes

Was the park easy to find onsite? $\square$ No $\square$ Somewhat $\square$ Yes

Date $(\mathrm{m} / \mathrm{d} / \mathrm{yr})$ : I I I

Approximate Temperature: __ ${ }^{\circ} \mathrm{F} \quad$ Weather: $\square$ Clear $\square$ Partly Cloudy $\square$ Rain/Snow

Start Time: ___ am or pm (circle) End Time: ___ am or pm (circle) Length of visit: __ $\min$

Comments on Park Information: 


\section{Section 2: Access and Surrounding Neighborhood}

This section asks about factors related to accessing the park and about features of the neighborhood surrounding the park. Several questions include follow-up responses if you answered yes. After completing all questions, provide any additional comments in the space at the end of the section. When thinking about the surrounding neighborhood, consider all areas that are visible from all sides of the park.

When rating the access and surrounding neighborhood, please use the following definition:

- Useable: everything necessary for use is present and nothing prevents use (e.g., sidewalks are passable)

1. Can the park be accessed for use? (e.g., not locked/fenced, available for activity, etc.) $\square$ No $\square$ Yes

2. Are there signs that state the following (could be same sign)? (check all that are present)
$\square$ Park name
$\square$ Park hours
$\square$ Park contact information
$\square$ Park/facility rental information
$\square$ Park rules $\square$ Park map
$\square$ Rental equipment information
$\square$ Event/program information

3. How many points of entry does the park have? $\square$ More than 5 (or park boundary is open) $\square 2-5 \quad \square$ Only 1

4. Is there a public transit stop within sight of the park? $\square$ No $\square$ Yes

5. What types of parking are available for the park? (check all that are present)

$\square$ None $\square$ Parking Lot $\square$ On street parking $\square$ Bike rack(s)

6. Are there sidewalks on any roads adjacent to the park? (could be on opposite side of road) $\square$ No $\quad \square$ Yes If yes ... Are they useable? $\square$ All or most are useable $\square$ About half $\square$ None or few useable If yes ... Are there curb cuts and/or ramps on any sidewalks bordering or entering the park? $\square$ No $\square$ Yes

7. Is there an external trail or path connected to the park? $\square$ No $\square$ Yes

If yes... Is it useable? $\square$ No $\square$ Yes

8. Are there bike routes on any roads adjacent to the park? (check all that are present)

$\square$ None $\square$ Marked lane $\square$ Designated route sign $\square$ Share the road signs/markers

9. Are there nearby traffic signals on any roads adjacent to the park? (e.g., crosswalk, stop light/sign) $\square$ No $\square$ Yes

10. What are the main land use(s) around the park? (check all that apply)

$\square$ Residential $\square$ Commercial $\square$ Institutional (e.g., school) $\square$ Industrial (e.g., warehouse) $\square$ Natural

11. Which of the following safety or appearance concerns are present in the neighborhood surrounding the park?

(check all that are present in the surrounding neighborhood within sight on any side of the park)

$\square$ Inadequate lighting (e.g., absent or limited lighting on surrounding neighborhood streets)

Graffiti (e.g., markings or paintings that reduce the visual quality of the area)

Vandalism (e.g., damaged signs, vehicles, etc.)

Excessive litter (e.g., noticeable amounts of trash, broken glass, etc.)

$\square$ Heavy traffic (e.g., steady flow of vehicles)

Excessive noise (e.g., noticeable sounds that are unpleasant or annoying)

Vacant or unfavorable buildings (e.g., abandoned houses, liquor store)

Poorly maintained properties (e.g., overgrown grass, broken windows)

Lack of eyes on the street (e.g., absence of people, no houses or store fronts)

Evidence of threatening persons or behaviors (e.g., gangs, alcohol/drug use)

Other

Comments on Access or Surrounding Neighborhood Issues: 


\section{Section 3: Park Activity Areas}

This section asks about the activity areas in the park. For each activity area type:

1. First, indicate the number (\#) that are present in the park (if none, write " 0 ").

2. Then, respond to several subsequent questions about up to three of those particular areas. If there are more than three areas for a specific activity area type, rate the first three you encounter during the audit. If there were no activity areas of that type present in the park, move on to the next type.

3. Finally, use the space provided to note any additional comments about each type of activity area.

When rating the activity areas, please use the following definitions:

- Useable: everything necessary for use is present (excluding portable equipment - rackets, balls, etc.) and nothing prevents use (e.g., are there nets up for tennis courts, goals for sport fields, are trails passable, etc.)

- Good condition: looks clean and maintained (e.g., minimal rust, graffiti, broken parts; even surface; etc.)

\begin{tabular}{|c|c|c|c|c|}
\hline 12. Activity Areas & Area 1 & Area 2 & \multicolumn{2}{|c|}{ Area 3} \\
\hline a. Playground & & & & \\
\hline Useable & $\square$ Yes & $\square$ Yes & $\square$ No & $\square$ Yes \\
\hline Good condition & $\square$ Yes & $\square$ Yes & $\square$ No & $\square$ Yes \\
\hline Distinct areas for different age groups & $\square$ Yes & $\square$ Yes & $\square$ No & $\square$ Yes \\
\hline Colorful equipment (i.e., 3+ colors) & $\square$ Yes & $\square$ Yes & $\square$ No & $\square$ Yes \\
\hline Shade cover for some $(25 \%+)$ of the area & $\square$ Yes & $\square$ Yes & $\square$ No & $\square$ Yes \\
\hline Benches in/surrounding area & $\square$ Yes & $\square$ Yes & $\square$ No & $\square$ Yes \\
\hline Fence around area (i.e., half or more) & $\square$ Yes & $\square$ Yes & $\square$ No & $\square$ Yes \\
\hline Separation or distance from road & $\square$ Yes & $\square$ Yes & $\square$ No & $\square$ Yes \\
\hline
\end{tabular}

Comments:

\begin{tabular}{llllll}
\hline b. Sport Field (football/soccer) & (\#:__) & & & & \\
Useable & & $\square$ No $\square$ Yes & $\square$ No $\square$ Yes & $\square$ No $\square$ Yes \\
Good condition & $\square$ No $\square$ Yes & $\square$ No $\square$ Yes & $\square$ No $\square$ Yes \\
Comments: & & & & &
\end{tabular}

\begin{tabular}{lllll}
\hline c. Baseball Field & $\left(\#: \_\right)$ & & & \\
Useable & & $\square$ No $\square$ Yes & $\square$ No $\square$ Yes & $\square$ No $\square$ Yes \\
Good condition & & $\square$ No $\square$ Yes & $\square$ No $\square$ Yes & $\square$ No $\square$ Yes
\end{tabular}

Comments:

\begin{tabular}{|c|c|c|c|c|c|c|c|}
\hline $\begin{array}{l}\text { d. Swimming Pool } \\
\text { Useable } \\
\text { Good condition } \\
\text { Comments: }\end{array}$ & (\# : _ & $\begin{array}{l}\square \text { No } \\
\square \text { No }\end{array}$ & $\begin{array}{l}\square \text { Yes } \\
\square \text { Yes }\end{array}$ & $\begin{array}{l}\square \text { No } \\
\square \text { No }\end{array}$ & $\begin{array}{l}\square \text { Yes } \\
\square \text { Yes }\end{array}$ & $\begin{array}{l}\square \text { No } \\
\square \text { No }\end{array}$ & $\begin{array}{l}\square \text { Yes } \\
\square \text { Yes }\end{array}$ \\
\hline e. Splash Pad & (\# :__ & & & & & & \\
\hline Useable & & $\square$ No & $\square$ Yes & $\square$ No & $\square$ Yes & $\square$ No & $\square$ Yes \\
\hline Good condition & & $\square$ No & $\square$ Yes & $\square$ No & $\square$ Yes & $\square$ No & $\square$ Yes \\
\hline
\end{tabular}

\begin{tabular}{llllll}
\hline $\begin{array}{l}\text { f. Basketball Court } \\
\text { Useable }\end{array}$ & (\#:_) & & & & \\
Good condition & & $\square$ No $\square$ Yes & $\square$ No $\square$ Yes & $\square$ No $\square$ Yes \\
Comments: & & $\square$ No $\square$ Yes & $\square$ No $\square$ Yes & $\square$ No $\square$ Yes \\
\hline
\end{tabular}

g. Tennis Court

Useable

$(\#: \underline{1})$

Good condition

$\square$ No $\square$ Yes $\square$ No $\square$ Yes $\square$ No $\square$ Yes

Comments: 


\begin{tabular}{|c|c|c|c|}
\hline Activity Areas & Area 1 & Area 2 & Area 3 \\
\hline $\begin{array}{l}\text { h. Volleyball Court } \\
\text { Useable } \\
\text { Good condition } \\
\text { Comments: }\end{array}$ & $\begin{array}{ll}\square \text { No } & \square \text { Yes } \\
\square \text { No } & \square \text { Yes }\end{array}$ & $\begin{array}{ll}\square \text { No } & \square \text { Yes } \\
\square \text { No } & \square \text { Yes }\end{array}$ & $\begin{array}{ll}\square \text { No } & \square \text { Yes } \\
\square \text { No } & \square \text { Yes }\end{array}$ \\
\hline $\begin{array}{l}\text { i. Trail } \\
\text { Useable } \\
\text { Good condition } \\
\text { Connected to activity areas } \\
\text { Distance markers/sign } \\
\text { Benches along trail } \\
\text { What is the trail surface? (check one) }\end{array}$ & $\begin{array}{l}\square \text { No } \square \text { Yes } \\
\square \text { No } \square \text { Yes } \\
\square \text { No } \square \text { Yes } \\
\square \text { No } \square \text { Yes } \\
\square \text { No } \square \text { Yes } \\
\square \text { Paved } \\
\square \text { Crushed stone } \\
\square \text { Dirt/mulch }\end{array}$ & $\begin{array}{l}\square \text { No } \square \text { Yes } \\
\square \text { No } \square \text { Yes } \\
\square \text { No } \square \text { Yes } \\
\square \text { No } \square \text { Yes } \\
\square \text { No } \square \text { Yes } \\
\square \text { Paved } \\
\square \text { Crushed stone } \\
\square \text { Dirt/mulch }\end{array}$ & $\begin{array}{l}\square \text { No } \square \text { Yes } \\
\square \text { No } \square \text { Yes } \\
\square \text { No } \square \text { Yes } \\
\square \text { No } \square \text { Yes } \\
\square \text { No } \square \text { Yes } \\
\square \text { Paved } \\
\square \text { Crushed stone } \\
\square \text { Dirt/mulch }\end{array}$ \\
\hline 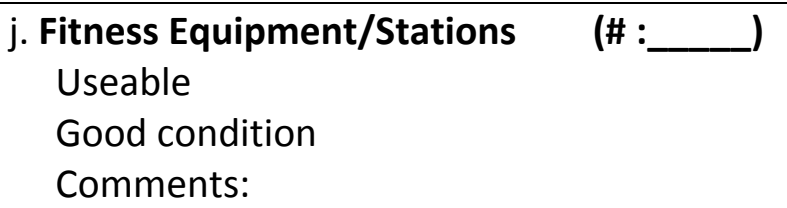 & $\begin{array}{ll}\square \text { No } & \square \text { Yes } \\
\square \text { No } & \square \text { Yes }\end{array}$ & $\begin{array}{ll}\square \text { No } & \square \text { Yes } \\
\square \text { No } & \square \text { Yes }\end{array}$ & $\begin{array}{l}\square \text { Yes } \\
\square \text { Yes }\end{array}$ \\
\hline $\begin{array}{l}\text { k. Skate Park } \\
\text { Useable } \\
\text { Good condition } \\
\text { Comments: }\end{array}$ & $\begin{array}{ll}\square \text { No } & \square \text { Yes } \\
\square \text { No } & \square \text { Yes }\end{array}$ & $\begin{array}{ll}\square \text { No } & \square \text { Yes } \\
\square \text { No } & \square \text { Yes }\end{array}$ & $\begin{array}{l}\square \text { Yes } \\
\square \text { Yes }\end{array}$ \\
\hline $\begin{array}{l}\text { I. Off-Leash Dog Park } \\
\text { Useable } \\
\text { Good condition } \\
\text { Comments: }\end{array}$ & $\begin{array}{ll}\square \text { No } & \square \text { Yes } \\
\square \text { No } & \square \text { Yes }\end{array}$ & $\begin{array}{ll}\square \text { No } & \square \text { Yes } \\
\square \text { No } & \square \text { Yes }\end{array}$ & $\begin{array}{ll}\square \text { No } & \square \text { Yes } \\
\square \text { No } & \square Y e s\end{array}$ \\
\hline $\begin{array}{l}\text { m. Open/Green Space } \\
\text { Useable } \\
\text { Good condition } \\
\text { Comments: }\end{array}$ & $\begin{array}{ll}\square \text { No } & \square \text { Yes } \\
\square \text { No } & \square Y e s\end{array}$ & $\begin{array}{ll}\square \text { No } & \square \text { Yes } \\
\square \text { No } & \square Y e s\end{array}$ & $\begin{array}{ll}\square \text { No } & \square \text { Yes } \\
\square \text { No } & \square Y e s\end{array}$ \\
\hline $\begin{array}{l}\text { n. Lake } \\
\text { Useable } \\
\text { Good condition } \\
\text { Is there a designated swimming area? } \\
\text { Comments: }\end{array}$ & $\begin{array}{ll}\square \text { No } & \square Y e s \\
\square \text { No } & \square Y e s \\
\square \text { No } & \square Y e s\end{array}$ & $\begin{array}{ll}\square \text { No } & \square \text { Yes } \\
\square \text { No } & \square Y e s \\
\square \text { No } & \square \text { Yes }\end{array}$ & $\begin{array}{l}\square \text { Yes } \\
\square \text { Yes } \\
\square \text { Yes }\end{array}$ \\
\hline $\begin{array}{l}\text { o. Other (fill in a type description for each) } \\
\text { Useable } \\
\text { Good condition } \\
\text { Comments: }\end{array}$ & $\begin{array}{ll}\text { No } & \square Y e s \\
\square \text { No } & \square Y e s\end{array}$ & $\begin{array}{ll}\text { No } & \square Y e s \\
\square \text { No } & \square Y e s\end{array}$ & $\begin{array}{ll}\text { No } & \square Y e s \\
\square \text { No } & \square Y e s\end{array}$ \\
\hline
\end{tabular}

Comments on Park Activity Areas: 


\section{Section 4: Park Quality and Safety}

This section asks about factors related to comfort and safety when using the park. Several questions include follow-up responses if you answered yes. After completing all questions, provide any additional comments in the space at the end.

When rating the quality and safety features of the park, please use the following definitions:

- Useable: everything necessary for use is present and nothing prevents use (e.g., can get into restrooms, drinking fountains work, etc.)

- Good condition: looks clean and maintained (e.g., minimal rust, graffiti, broken parts; etc.)

13. Are there public restroom(s) or portable toilet(s) at the park? $\square$ No $\square$ Yes If yes...

Are the restroom(s) useable? $\square$ All or most are useable $\square$ About half $\square$ None or few are useable Are they in good condition? $\square$ All or most in good condition $\square$ About half $\square$ None or few in good condition Is there a family restroom? $\square$ No $\square$ Yes Is there a baby change station in any restroom? $\square$ No $\square$ Yes

14. Are there drinking fountain(s) at the park? $\square$ No $\square$ Yes If yes...

How many different fountains are there? (i.e., units, not spouts)

Are the fountains useable? $\square$ All or most are useable Are they in good condition? $\square$ All or most in good condition Are they near activity areas? $\square$ All or most are near

$\square$ About half $\square$ None or few are useable $\square$ About half $\square$ None or few in good condition $\square$ About half $\square$ None or few are near

15. Are there bench(es) to sit on in the park? $\square$ No $\square$ Yes If yes...

Are the benches useable? $\square$ All or most are useable Are they in good condition? $\square$ All or most in good condition

$\square$ About half $\square$ None or few are useable $\square$ About half $\square$ None or few in good condition

16. Are there picnic table(s) in the park? $\square$ No $\square$ Yes If yes...

Are the tables useable? $\square$ All or most are useable Are they in good condition? $\square$ All or most in good condition Is there a picnic shelter in the park? $\square$ No $\square$ Yes Is there a grill or fire pit in the park? $\square$ No $\square$ Yes

17. Are there trash cans in the park? $\square$ No $\square$ Yes If yes...

Are they overflowing with trash? $\square$ All or most overflowing Are they near activity areas? $\square$ All or most are near About half $\square$ None or few are useable About half $\square$ None or few in good condition Are recycling containers provided? $\square$ No $\square$ Yes

About half $\square$ None or few overflowing About half $\square$ None or few are near

18. Is there food/vending machines available in the park? $\square$ No $\square$ Yes

19. If the sun was directly overhead, how much of the park would be shaded? $\square<25 \% \quad \square 25-75 \% \quad \square>75 \%$

20. Are there rules posted about animals in the park? (e.g., dogs must be leashed)? $\square$ No $\square$ Yes

21. Is there a place to get dog waste pick up bags in the park? $\square$ No $\square$ Yes If yes ... Are bags available at any of the locations? $\square$ No $\square$ Yes 
22. Are there lights in the park? (not including neighborhood street lights) $\square$ No $\quad \square$ Yes If yes...

How much of the park could be lit? $\square<25 \% \quad \square 25-75 \% \quad \square>75 \%$

Are the activity areas lit? $\square$ All or most are lit $\square$ About half $\square$ None or few are lit

23. Is the park monitored? (e.g., volunteer or paid staff, patrolled by police, cameras, etc.) $\square$ Unsure $\square$ Yes

24. Are there any emergency devices in the park? (e.g., phone, button, emergency directions) $\square$ No $\square$ Yes

25. Is there evidence of threatening behavior or persons in the park? (e.g., gangs, alcohol/drug use) $\square$ No $\square$ Yes

26. From the center of the park, how visible is the surrounding neighborhood? $\square$ Fully $\square$ Partially $\square$ Not at all

27. Are there road(s) of any type through the park? $\square$ No $\square$ Yes

If yes ... Are there traffic control mechanisms on the roads within the park? (e.g., crosswalk, stop light or sign, brick road, speed bumps, roundabouts) $\square$ No $\square$ Yes

28. Which of the following park quality concerns are present in the park? (check all that are present)

$\square$ Graffiti (e.g., markings or paintings that reduce the visual quality of the area)

Vandalism (e.g., damaged signs, buildings, equipment, etc.)

Excessive litter (e.g., noticeable amounts of trash, broken glass, etc.)

Excessive animal waste (e.g., noticeable amounts of dog waste)

Excessive noise (e.g., noticeable sounds that are unpleasant or annoying)

Poor maintenance (e.g., overgrown grass/weeds/bushes or lack of grass in green areas)

Other

29. What aesthetic features are present in the park? (check all that are present)

Evidence of landscaping (e.g., flower beds, pruned bushes)

Artistic feature (e.g., statue, sculpture, gazebo, fountain)

Historical or educational feature (e.g., monument, nature display, educational signs, etc.)

Wooded area (e.g., thick woods or dense trees)

Trees throughout the park (e.g., scattered trees)

Water feature (e.g., lake, stream, pond)

Meadow (e.g., natural, tall grassy area)

Other

30. Are there any dangerous spots in the park? (e.g., abandoned building, pit/hole) $\square$ No $\square$ Yes

Comments on Park Quality and Safety Issues:

Before finishing, please ensure you have answered all questions in the tool.

\section{About the Community Park Audit Tool}

The Community Park Audit Tool (CPAT) was developed in 2010 in Kansas City, Missouri by Andrew Kaczynski (Kansas State University) and Sonja Wilhelm Stanis (University of Missouri) in collaboration with the City of Kansas City Missouri Parks and Recreation Department. Development of the CPAT was supported by a grant from Active Living Research, a national program of the Robert Wood Johnson Foundation. 
TABLE 1: Descriptions and Examples of Pocket, Neighborhood, and Community Parks

\begin{tabular}{|c|c|c|c|}
\hline & \multicolumn{3}{|c|}{ Park Type } \\
\hline & Pocket & Neighborhood & Community \\
\hline Size & Range from $1 / 8$ to 1 acre & Range from 2 to 10 acres & Range from 10 acres to over 50 acres \\
\hline Access/Serves & $\begin{array}{l}\text { Parking is typically not provided. Accessed by } \\
\text { pedestrian and bicycle means. }\end{array}$ & $\begin{array}{l}\text { Parking spaces available. Accessible to residents } \\
\text { who live within a one-half mile radius. Generally } \\
\text { located away from major arterial streets. Typically } \\
\text { serves one large or several smaller neighborhoods. }\end{array}$ & $\begin{array}{l}\text { Located near major thoroughfare. Typically meant } \\
\text { to be driven to. Serves a group of neighborhoods } \\
\text { or a portion of a city. }\end{array}$ \\
\hline Features & $\begin{array}{l}\text { Benches, landscaping, and other "focal" features } \\
\text { are common items. }\end{array}$ & $\begin{array}{l}\text { Shaded playgrounds, unlighted practice fields, } \\
\text { lighted multi-purpose courts for basketball and } \\
\text { volleyball, active areas for unorganized play, } \\
\text { picnic areas, benches, tables, and short trails. }\end{array}$ & $\begin{array}{l}\text { Shaded playgrounds, lighted ball fields and courts, } \\
\text { restrooms, recreation centers, aquatic centers, and } \\
\text { large parking lots. }\end{array}$ \\
\hline Example & Chihuahuita Park & Madeline Park & Memorial Park \\
\hline
\end{tabular}


TABLE 2: Number of Parks by Park Type and Region (N=144)

\begin{tabular}{|l|cc|cc|cc|cc|}
\cline { 2 - 9 } \multicolumn{1}{c|}{} & \multicolumn{7}{c|}{ Park Type } \\
\hline Park Region & \multicolumn{2}{c|}{ Pocket } & \multicolumn{2}{c|}{ Neighborhood } & \multicolumn{2}{c|}{ Community } & \multicolumn{2}{c|}{ Total } \\
\hline Northeast & 2 & $4.7 \%$ & 13 & $17.3 \%$ & 6 & $23.1 \%$ & 21 & $14.6 \%$ \\
Central & 22 & $51.2 \%$ & 14 & $18.7 \%$ & 4 & $15.4 \%$ & 40 & $27.8 \%$ \\
East & 7 & $16.3 \%$ & 23 & $30.7 \%$ & 8 & $30.8 \%$ & 38 & $26.4 \%$ \\
Northwest & 8 & $18.6 \%$ & 16 & $21.3 \%$ & 2 & $7.7 \%$ & 26 & $18.1 \%$ \\
Mission Valley & 4 & $9.3 \%$ & 9 & $12.0 \%$ & 6 & $23.1 \%$ & 19 & $13.2 \%$ \\
\hline Total & $\mathbf{4 3}$ & & $\mathbf{7 5}$ & & $\mathbf{2 6}$ & & $\mathbf{1 4 4}$ \\
\hline
\end{tabular}


Social Determinants of Health

Median Total Population

Number of Households

Sex

Male population (\%)

Female population $(\%)$

Median Age (years)

Civilian Labor Force Unemployed Rate (\%)

Income

Median household income (US Dollars) (2009 inflation adjusted)

Mean household income (US Dollars) (2009 inflation adjusted)

Nativity

Native born (\%)

Foreign-born $(\%)$

Race

White $(\%)$

Black or African American (\%)

American Indian and Alaska Native (\%)

Asian (\%)

Native Hawaiian and Other Pacific Islander (\%)

Some other race $(\%)$

Ethnicity

Hispanic or Latino (of any race) $(\%)$

$$
\text { Mexican Descent (\%) }
$$

Educational Attainment

Less than 9th grade (\%)

9th to 12 th grade, no diploma (\%)

High school graduate (includes equivalency) $(\%)$

Some college, no degree (\%)

Associate's degree $(\%)$

Bachelor's degree (\%)

Graduate or professional degree (\%)

\section{Park Measures}

Park Availability

Park Features

Total Park Facilities

Number of playgrounds

Number of sports fields

Number of baseball fields

Number of swimming pools

Number of splash pads

Number of basketball courts

Number of tennis courts

Number of volleyball courts

Number of trails

Number of fitness stations

Number of skate parks

Number of off-leash dog parks

Number of open/green space

Number of lakes

\begin{tabular}{|c|c|}
\hline Median & (Q1, Q3) \\
\hline 5934.0 & $(4182.5,8358.0)$ \\
\hline 2156.5 & $(1393.0,3015.0)$ \\
\hline 47.1 & $(44.2,49.6)$ \\
\hline 53.0 & $(50.4,55.8)$ \\
\hline 32.3 & $(27.2,34.9)$ \\
\hline 7.1 & $(5.1,8.8)$ \\
\hline 33800.50 & $(22041.00,49137.00)$ \\
\hline 46191.00 & $(31436.70,58278.00)$ \\
\hline 72.1 & $(66.7,78.3)$ \\
\hline 28.0 & $(21.7,33.3)$ \\
\hline 78.8 & $(73.9,84.7)$ \\
\hline 2.4 & $(1.4,3.8)$ \\
\hline 0.8 & $(0.4,1.3)$ \\
\hline 1.0 & $(0.0,2.7)$ \\
\hline 0.0 & $(0.0,0.0)$ \\
\hline 16.5 & $(12.5,20.2)$ \\
\hline 87.0 & $(70.0,93.1)$ \\
\hline 80.3 & $(65.0,89.5)$ \\
\hline 18.5 & $(7.9,28.4)$ \\
\hline 11.0 & $(7.7,14.8)$ \\
\hline 24.0 & $(19.8,26.2)$ \\
\hline 20.2 & $(16.0,25.0)$ \\
\hline 6.3 & $(4.0,7.8)$ \\
\hline 10.3 & $(4.7,17.5)$ \\
\hline 5.3 & $(2.1,8.7)$ \\
\hline Median & $(\mathbf{Q 1}, \mathbf{Q 3})$ \\
\hline 1.0 & $(1.0,2.0)$ \\
\hline Median & (Q1, Q3) \\
\hline 4.0 & $(2.0,7.0)$ \\
\hline Frequency & $\%$ \\
\hline 118.0 & 81.9 \\
\hline 27.0 & 18.8 \\
\hline 34.0 & 23.6 \\
\hline 7.0 & 4.9 \\
\hline 1.0 & 0.7 \\
\hline 60.0 & 41.7 \\
\hline 21.0 & 14.6 \\
\hline 4.0 & 2.8 \\
\hline 48.0 & 33.3 \\
\hline 5.0 & 3.5 \\
\hline 8.0 & 5.6 \\
\hline 1.0 & 0.7 \\
\hline 131.0 & 91.0 \\
\hline 0.0 & 0.0 \\
\hline
\end{tabular}


TABLE 3: Descriptive Analysis of Social Determinants of Health and Park Measures (N=144) (continued)

\section{Total Park Amenities}

Public transit stop

Parking lot

Sidewalks adjacent to park

Sidewalk - curbs or ramps

External trail to park

Restrooms

Drinking fountain

Benches

Picnic tables

Picnic shelter

Grill

Trash cans

Vending machines

Baby changing stations

Recycle containers

Animals rules

Dog waste bags

Emergency devices

Traffic control mechanisms

\section{Total Park Aesthetic Features}

Landscaping

Artistic feature

Historical/educational feature

Wooded area

Trees

Water feature

Meadow

\section{Park Characteristics}

\section{Total Park Quality Concerns}

Threatening behavior at park

Roads through park

Dangerous spots

Graffiti

Vandalism

Excessive litter

Excessive animal waste

Excessive noise

Poor maintenance

\section{Neighborhood Safety Concerns}

Inadequate lighting

Graffiti

Vandalism

Excessive litter

Heavy traffic

Excessive Noise

Vacant/unfavorable buildings

Poorly maintained properties

Lack of eyes

Threatening behavior
Median

7.0

Frequency

59.0

55.0

136.0

134.0

2.0

35.0

12.0

99.0

89.0

41.0

2.0

138.0

3.0

4.0

1.0

116.0

81.0

2.0

18.0

Median

1.0

Frequency

33.0

19.0

28.0

0.0

95.0

0.0

4.0

Median

1.5

Frequency

27.0

24.0

31.0

92.0

17.0

15.0

1.0

19.0

28.0

Median

2.0

Frequency

38.0

63.0

19.0

17.0

58.0

34.0

21.0

44.0

31.0

30.0
(Q1, Q3)

$(6.0,9.0)$

$\%$

41.0

38.2

94.4

93.1

1.4

24.3

8.3

68.8

61.8

28.5

1.4

95.8

2.1

2.8

0.7

80.6

56.3

1.4

12.5

(Q1, Q3)

$(1.0,2.0)$

$\%$

22.9

13.2

19.4

0.0

66.0

0.0

2.8

(Q1, Q3)

$(0.0,2.0)$

$\%$

18.8

16.7

21.5

63.9

11.8

10.4

0.7

13.2

19.4

(Q1, Q3)

$(1.0,4.0)$

$\%$

26.4

43.8

13.2

11.8

40.3

23.6

14.6

30.6

21.5

20.8 
TABLE 4: Bivariate Association of Park Features and Characteristics by Median Household Income and Percent Foreign-born Tertiles (N=144)

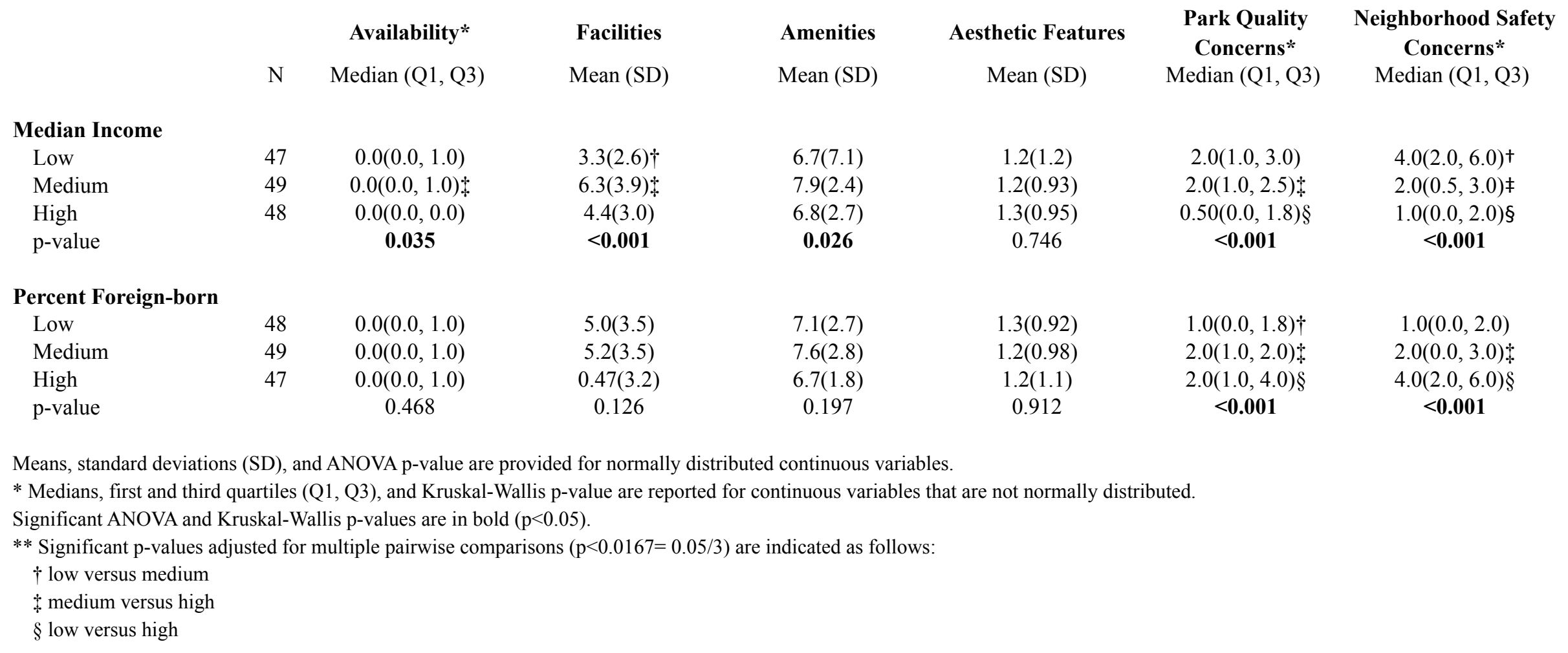




\section{Vita}

Born in El Paso, Texas, Amir Kamel is the proud son of Dr. and Mrs. Kamel. In 2008, after completing two Bachelor of Science Degrees in Biology and Microbiology from New Mexico State University, Amir decided to pursue a career in public health; and in 2009 he was accepted into the Master of Public Health Program at the University of Texas at El Paso. During his academic career in the MPH program Amir had the pleasure of serving as a president for the Students for Public Health (SPH), a research assistant for three public health science professors, and a member of Eta Sigma Gamma and Alpha Chi, all of which proved to be invaluable experiences. Under the direction of Dr. Paula Ford, Mr. Kamel put together a community workshop for addressing park issues in the City of El Paso and received two grants for his thesis project, one from the Hispanic Health Disparities Research Center (HHDRC) and the other from the Pan American Health Organization (PAHO). In 2011, he was awarded the prestigious Sandy Tyler Endowed Fellowship in Health Sciences, and in 2012, designated by the College of Health Sciences as the Outstanding Graduate Student of the MPH program. Following the completion of his MPH, Amir plans to continue his education and focus his attention on further

promoting health in the El Paso community. His interests include physical activity, obesity, health education, and preventive medicine.

Permanent address: 5829 Via Cuesta

El Paso, Texas 79912

This thesis was typed by Amir Kamel. 